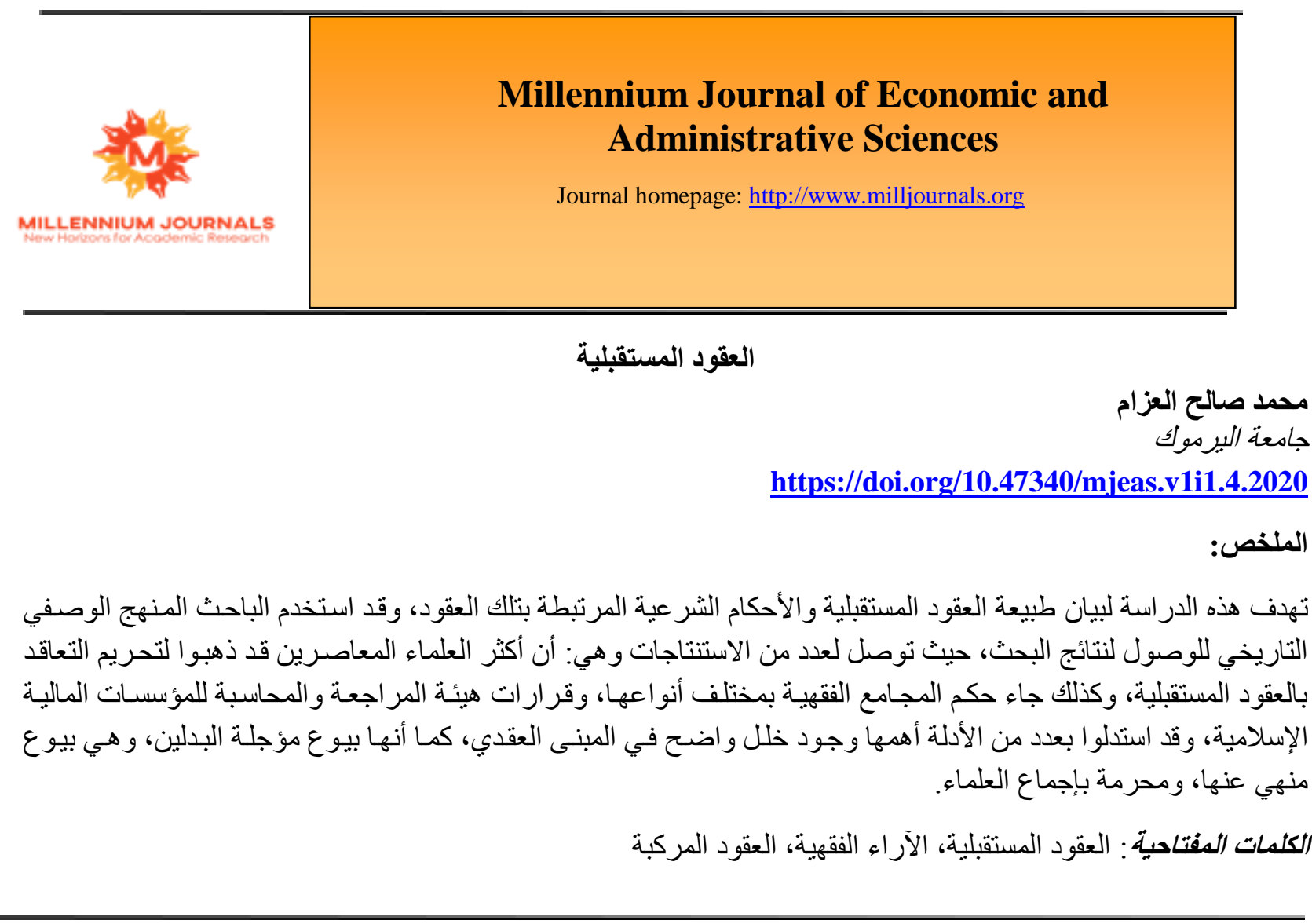

\title{
Futures Contracts
}

\section{Mohammed Saleh Al-Azzam} Yarmouk University

\begin{abstract}
This study aims to clarify the nature of future contracts and the legal rulings associated with those contracts. The researcher used the historical descriptive approach to reach the results of the research, as he reached a number of conclusions, namely: Fiqh councils and most contemporary scholars have prohibited using future contracts. Similarly, the Auditing and Accounting Authority for Islamic Financial Institutions supported this opinion. A number of evidences supported these opinions like the existence of a clear defect in the contract essence, in addition these activities are considered forbidden and prohibited by the consensus of scholars.
\end{abstract}

Keywords: future contracts, jurisprudential opinions, complex contracts 
بطلق المال في اللغة: على كل ما تملكه الإنسان من الأشياء، وفي الاصطلاح: اختلف الفقهاء في تعريف المال على النحو التالي: أـ عرف فقهاء الحنفية المال بتعريفات عديدة، فقال ابن عابدين: المر اد بالمال ما يميل إليه الطبع، ويمكن ادخاره لوقت الحاجـة،

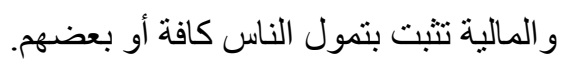

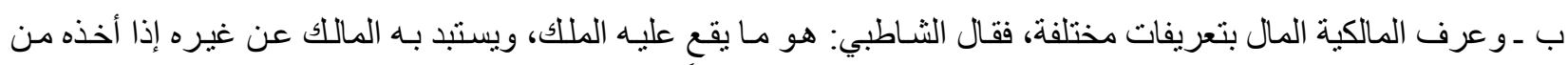

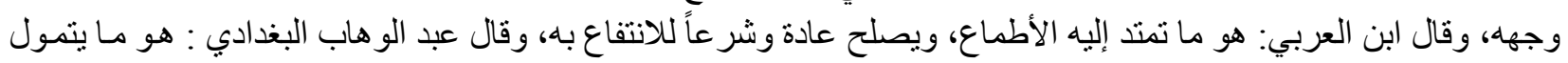
في العادة ويجوز أخذ العوض العن هنه.

ج - و عرف الزركثي من الثافعية المال بأنه ما كان منتفعاً به، أي مستعداً لأن ينتفع به، وحكى السيوطي عن الثـافعي أنه قال:

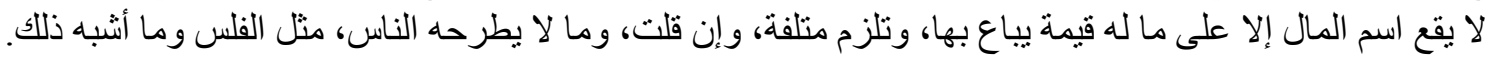

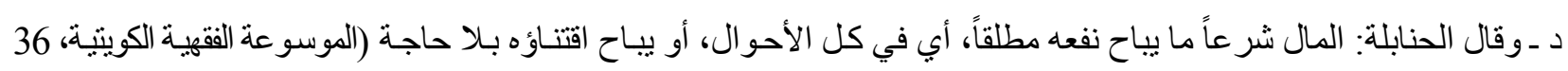

ما اختلف في ماليته:

اختلف الفقهاء في مالية المنافع، كما تباينت أنظار هم حول مالية الديون، وبيان ذلك فيما يلي: أ ـ مالية المنافع: المنافع: جمع منفعة، ومن أمثلتها عند الفقهاء: سكنى الدار ولبس الثوب وركوب الدابة، وقد اختلف الفقهاء في ماليتها على قولين:

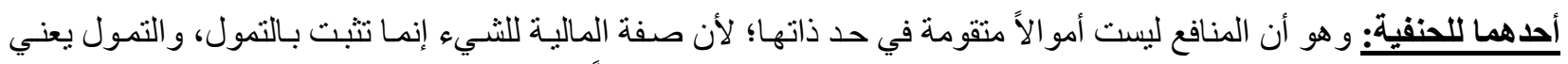

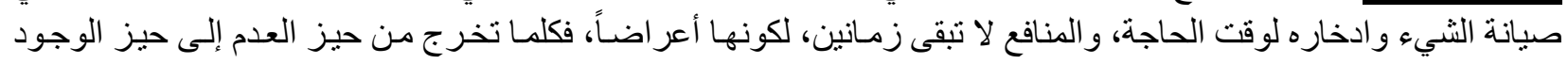
تتتلاشى، فلا يتصور فيهانة التمول.

غير أن الحنفية يعتبرون المنافع أموالاً متقومه إذا ورد عليها عقد معاوضة، كما في الإجارة، وذللك على خلاف القياس، وما كان على خلاف القياس فغيره عليه لا يقاس.

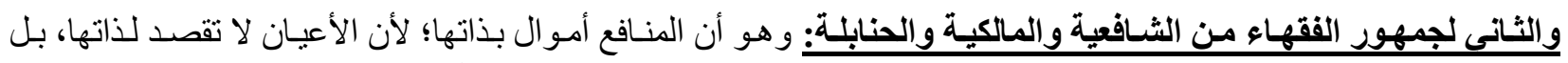

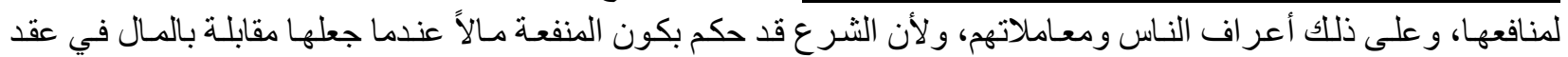

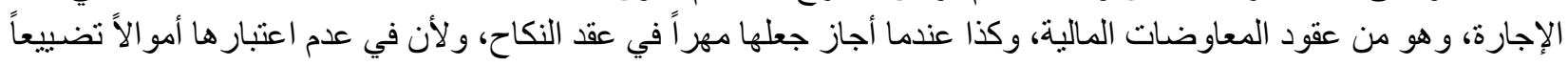

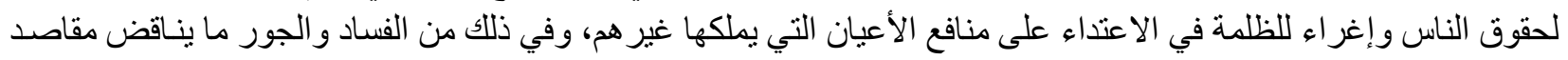
الثريعة و عدالتها.

وقال الثربيني الخطيب: المنافع ليست أمو الاً على الحقيقة، بـل على ضرب من التوسع و المجاز ، بدليل أنها معدومـة لا قدرة عليها.

بـ ـ مالية الديون: الدين في الاصطلاح الفقهي هو لزوم حق في الذمة، وقد يكون محلـه مـالاً، كمـا أنهـ قد يكون عملاً أو عبادة كصوم وصلاة وحج و غيرة ذللك.

و لا خلاف بين الفقهاء في أن الحق الواجب في الذمة إذا لم يكن مالياً، فإنه لا يعتبر مالاً، ولا يترتب عليه شيء من أحكامه. أما إذا كان الدين الثـاغل للذمة مالياً، فقد اختلف الفقهاء في اعتباره مالاً حقيقة، وذللك على قولين:

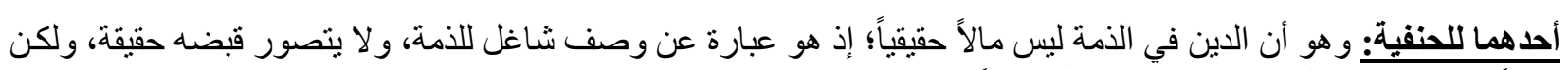

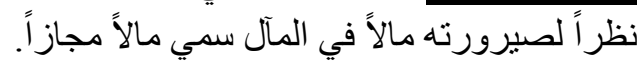

و الثانى قال الزركثى من الثافعية: الدين: هل هو مال في الحقبقة أو هو حق مطالبة يصير مالاً في المآل؟ فيه طريقان حكاهـا

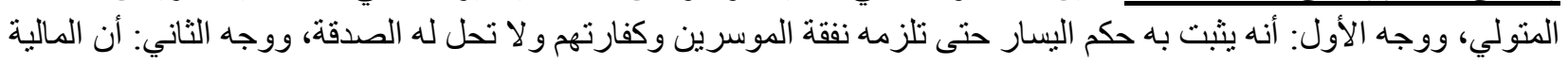




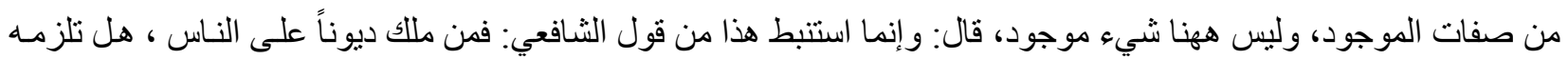

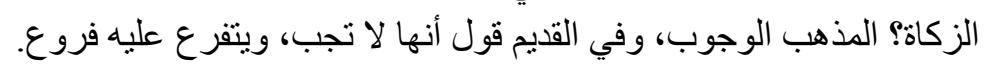

منها: هل يجوز بيع الدين من غير من عليه الدين؟ إن قلنا: إنه مال جاز ، أو حق فلا؛ لأن الحقوق لا تقبل النقل إلى الغير، ومنها:

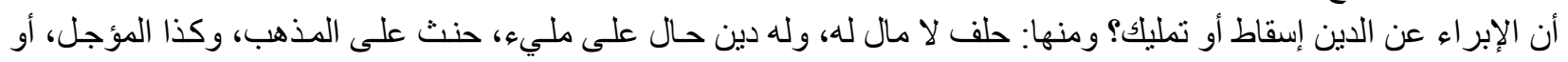
على المعسر في الأصح.

ثانياً: تقسيم الحقوق باعتبار المالية و عدمها: ( الموسوعة الفقهية الكويتية، 18 :40-41-). تنقسم الحقوق باعتبار المالية والتعلق بالأمو ال و عدم المالية إلى ما يأتي:

1- - حق مالي، يتعلق بالأمو ال، ويستعاض عنه بمال، مثل: الأعيان المالية حيث بمكن بيعها و الاستعاضة عنها بمال. 2 - حق مالي، ليس في مقابلة مال، مثل: المهر والنفقة، حيث يتعلق المهر بالزو اج و الدخول، وكلاهمـا ليس مـالاً، وكذللك النفقة

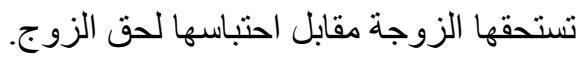

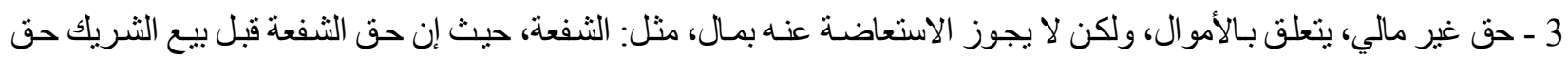

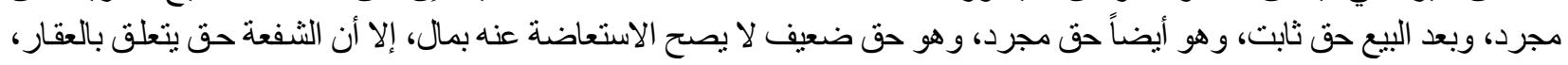
و هو مال بالإجماع.

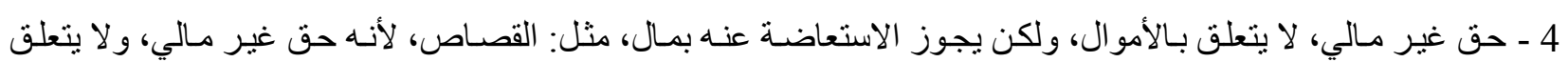

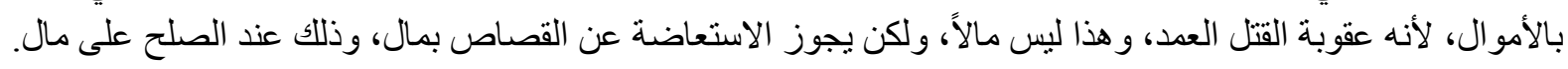
5 - حق غير مـالي، و لا يتعلق بـالاموال، ولا يجوز الاستعاضـة عنه بمـال، ولكن قد يترتب عليه حقوق ماليـة، مثل: الأبوة، و الأمومة، و البنوة.

6 - حق مختلف في ماليته، مثل: المنافع، حيث ذهب الجمهور إلى أن المنافع مـال، وذهب الحنفيـة إلى أنها لبست مـالاً ، وذكر الخطيب الثربيني أن المنافع يطلق عليها المال مجاز أ. ثالثاً: تفسير النهي عن بيعتين في بيعة في الأحاديث:

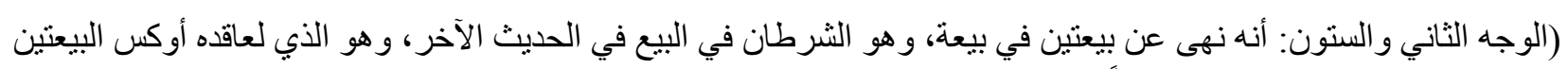

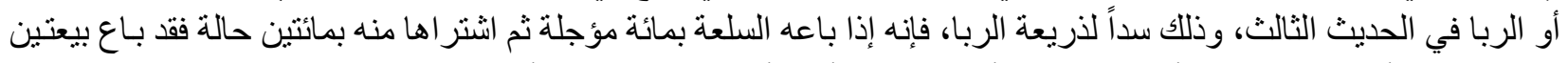

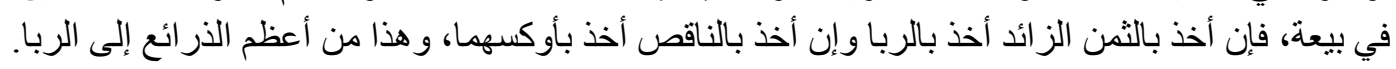

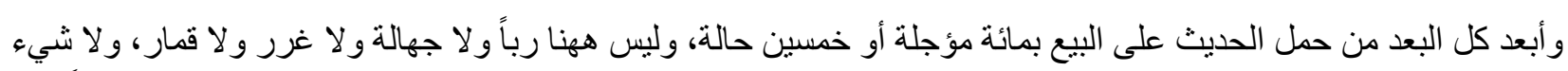

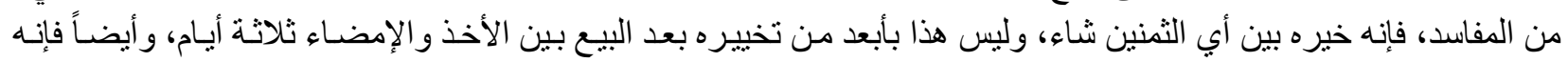

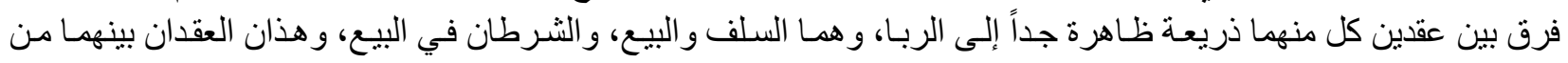

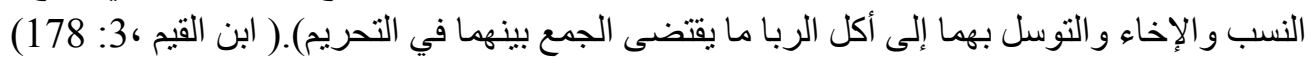

$$
\text { والبيعتين في بيعة: }
$$

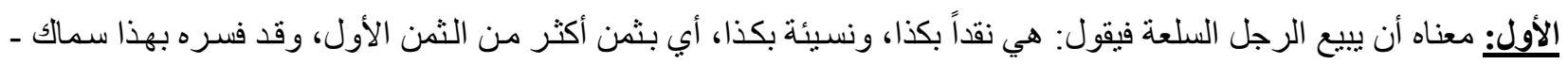

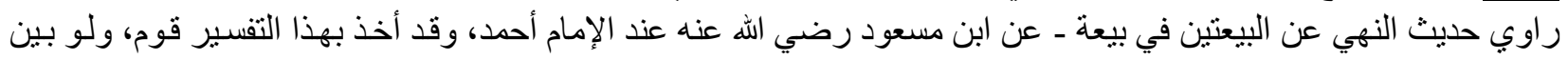
المتبايعان أحد الثمنين بعد ذلك، ومن هنا منعو الزين الزيادة في بيعة السلعة نسيئة عن سعر يومها.

الثانى: فسره بعضهم بالتفسير السابق نفسه، لكن بقيد الافتراق على الإبهام بين الثمنين، فقالو ا: معناه أن يقول: بعتك هذا نقدا

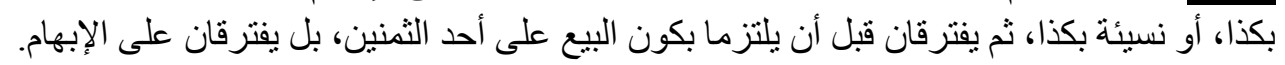


قال الثافعي: هو أن يقول: بعتلك هذا بألف نقداً أو ألفين إلى سنة، فخذ بأيهــا شُئت أنت وشئت أنـا، قال القاضـي من الثـافعية:

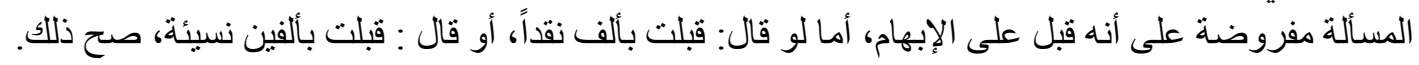
وفسره بذلك أبو عبيد و الثوري و إسحاق و المالكية والحنابلة أيضاً، مع تفسير هم له بتفسيرات أخرى كما بأتي. الثالث: قال مالك أيضاً: هو أن يشتري سلعة بدينار أو بشاة، أو يشتري بدينار شاة أو ثوباً، قد وجب أحدهما للمشتري.

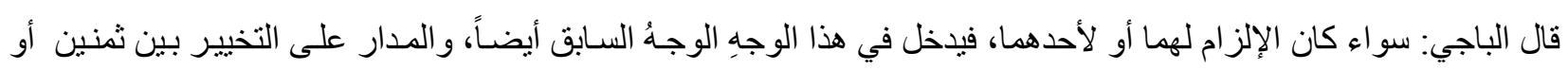
سلعتين مع الإلز ام بأحدهما لا بعينه.

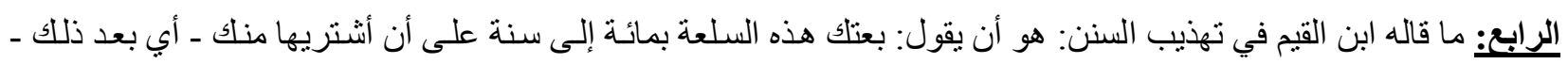

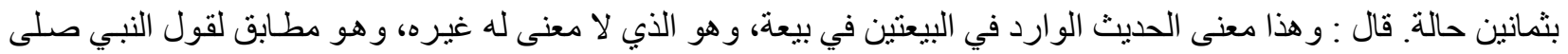

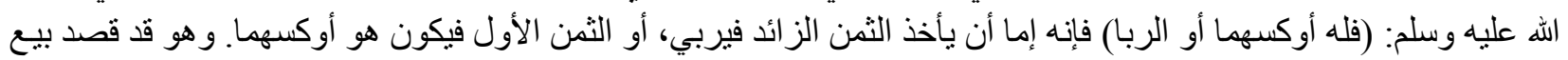

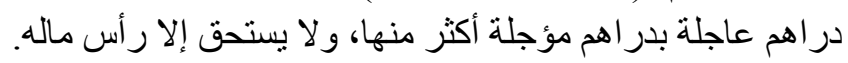

ووجه كونه من باب البيعتين في بيعة: أنهما بيعتان إحداهما بثمن مؤجل، و الأخرى بثمن معجل، وقد أبرمنا في صفقة واحدة.

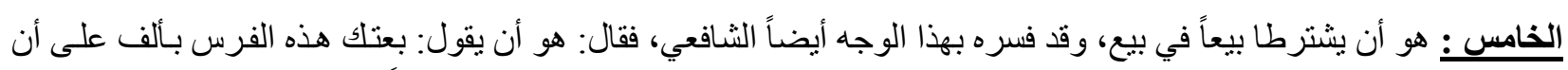

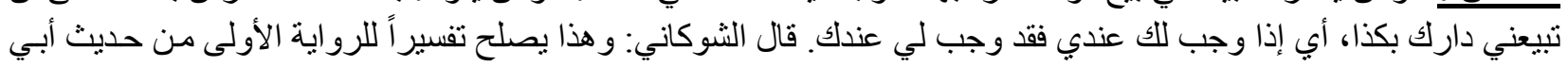

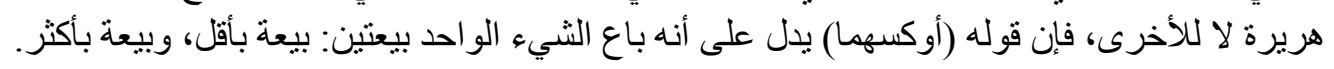

وجعل منه مسروق أن يقول: بعتلك هذا البز بكذا وكذا دينار اً تعطيني بالدينار عشرة در اهم، أي لأنه جمع بين بيع وصرف.

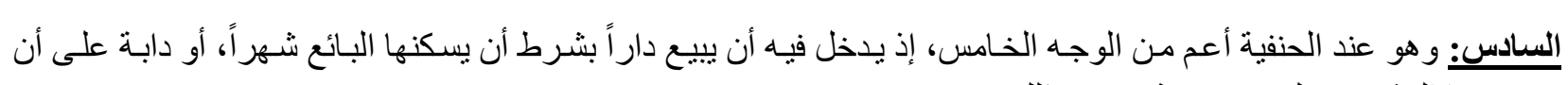
بيتخدمها المشتري ولو مدة معينة، ونحو ذللك.

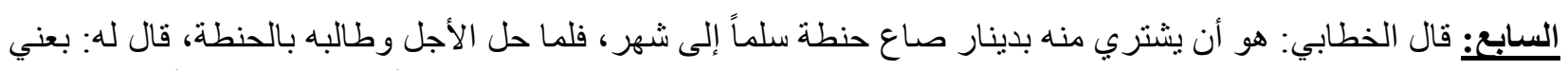

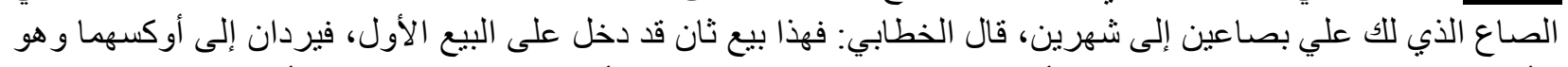

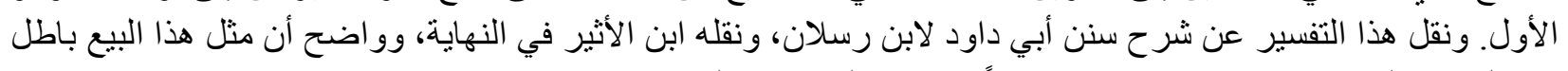

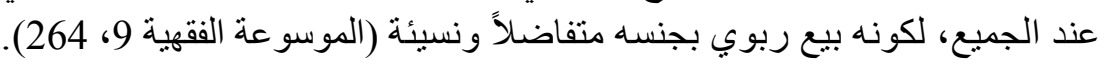

الألفاظ ذات الصلة:

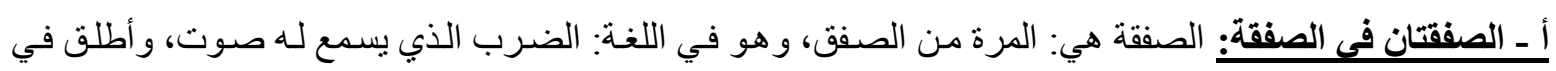

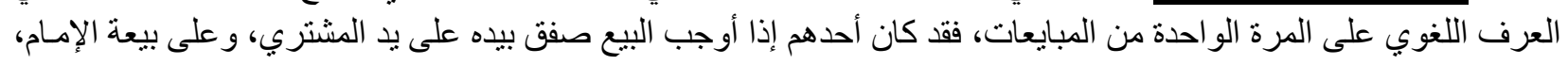

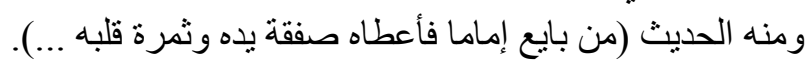
وتطلق الصفقة في الاصطلاح كذلك على البيعة و على غير ها من العقود، فالمرة من الإجارة صفقة، ومن القرض صفقة، وهكذا.

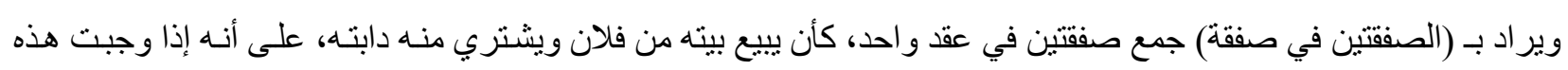

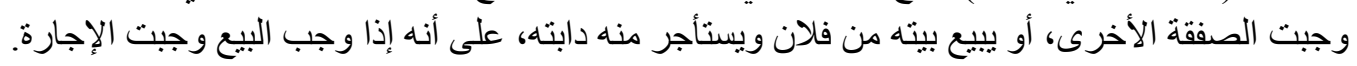
فاصطلاح (الصفقتين في صفقة) أعم من اصطلاح (البيعتين في بيعة). بـ ـ البيع و الثـرط: ولبيع و الثرط أعم من البيعتين في بيعـة؛ لأن الاشتر اطقد يكون اشتر اط عقد آخر ، وقد يكون اشتر اطاً لمصلحة أحد المتعاقدين، من غير وأن يكون المشروط عقداً آخر ). الإسلام حرم الربا، وحرم كل ما يؤدي إليه سداً لذريعة الربا، لأنه من حام حول الحمى يوشك أن يرتع فئها، والإسـام مـا حرم شيئًا وبشعه أكثر من الربا.

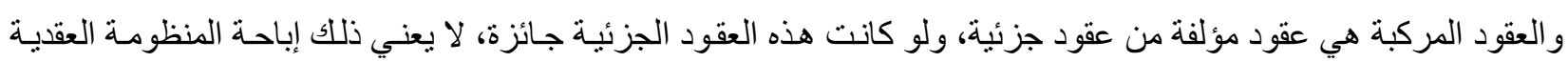

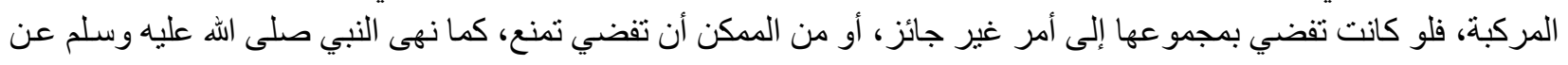




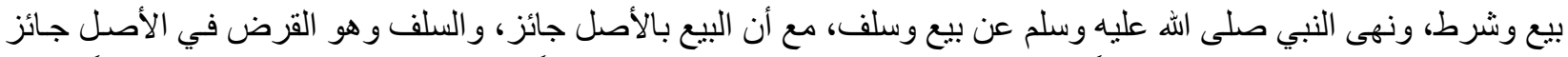

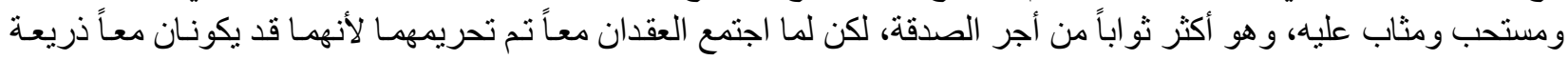
إلى الربا، فقد يشتري بثمن أعلى ومنفعة زائدة لأنه أسلفه و أقرضه.

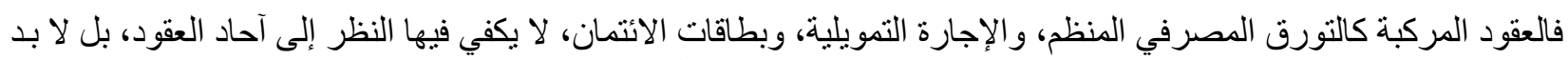

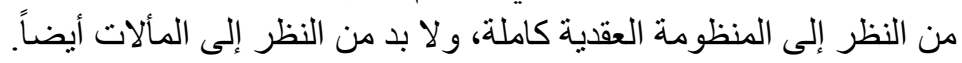

وفي بيع العينة أيضاً بيعتان في بيعة، حيث أن طالب التمويل يريد الحصول على السيولة، فيشتري السلعة بثمن مؤجل مرتفع، ثم

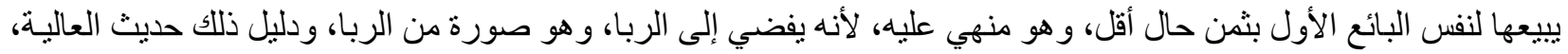

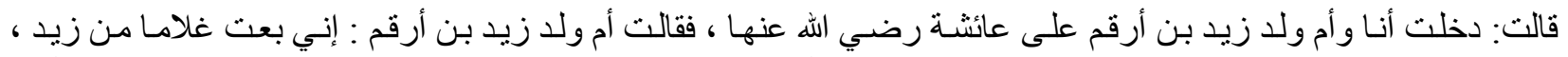

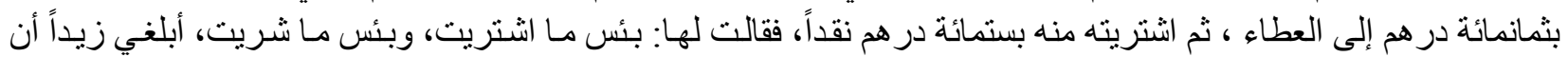

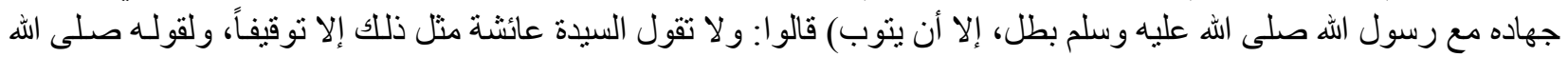

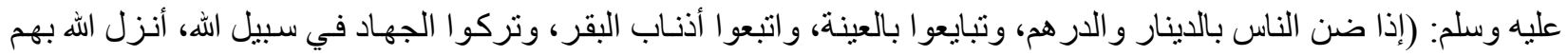
بلاء، فلا ير فعه حتى ير اجعو الدينهم).

ففي بيع العينة هما بيعتان، ولو كانت كل واحدة منهما لوحدها لكانت جائزة، لكن لما اجتمعتا في عقد واحد آلتا إلى نتيجة واحدة

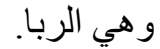

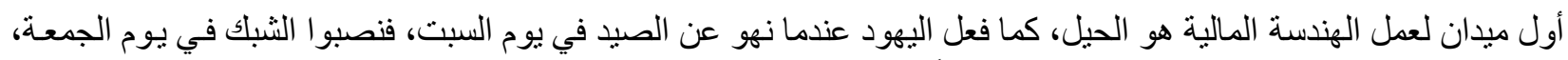

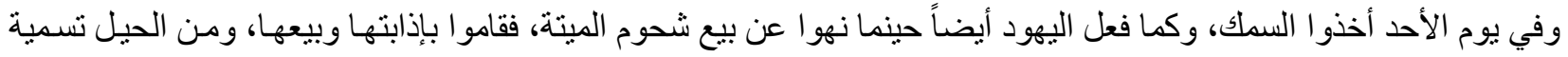

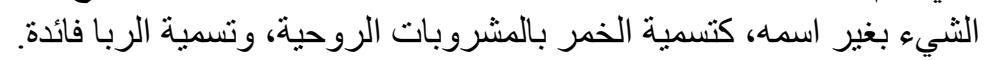

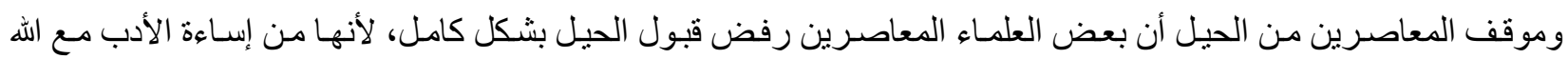

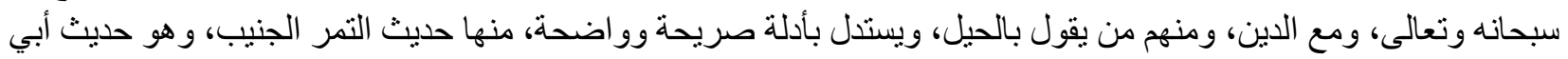

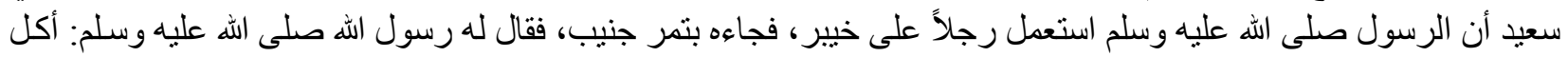

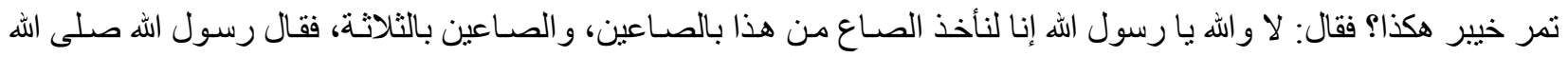

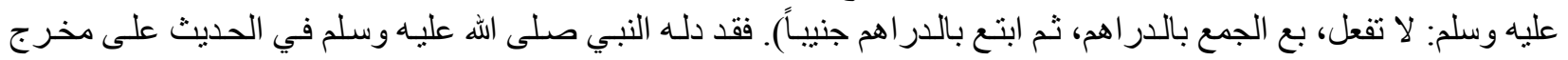
شر عي للخروج من دائرة الربا.

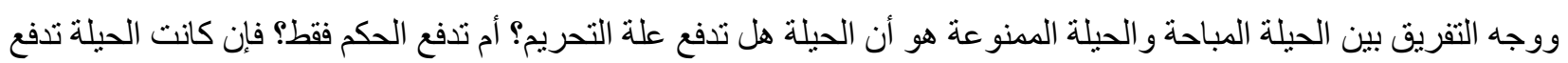

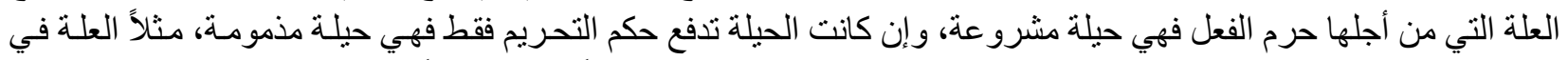

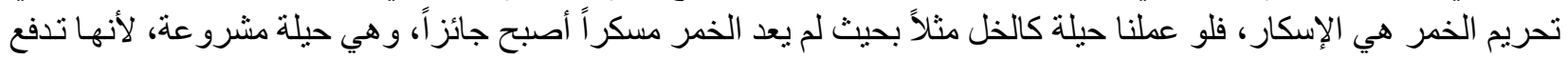

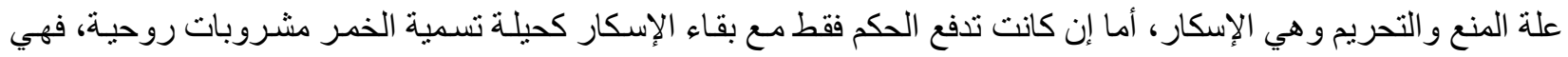

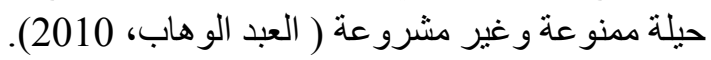

عقود المستقبليات

المستقليات هي نوع من أنواع المشتقات المالية، وهي عقود فر عية تبنى وتشتق من عقود أساسية لأدو ات استثمارية، لينشـأ عن

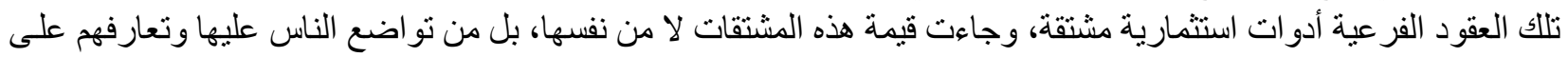

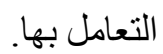

الأسو اق المالية تعيش حالياً أزمة كبيرة بعد انكثاف عيوب المعاملات التي تتعامل بها من المشتقات، حيث أن أهم الأهداف لهذهاه

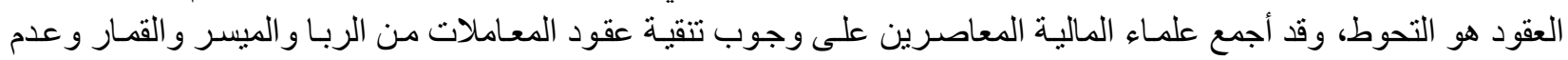

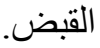

صحيح أن لا يمكن تصور نظام مالي بدون أسواق مالية، ولكن من غير المعقول تصور أنه لا يمكن وجود أسواق مالية إلا بهذه إنها

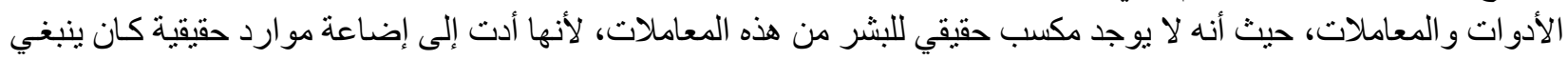

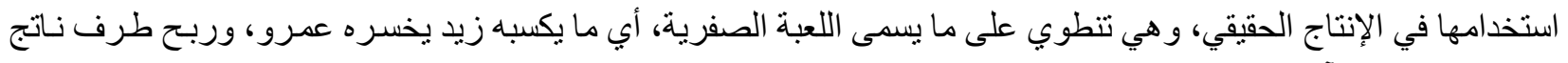

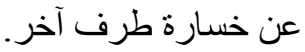




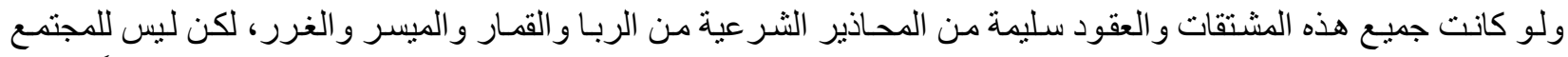

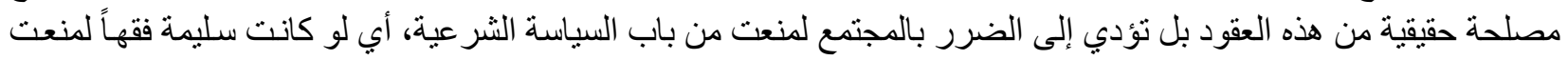

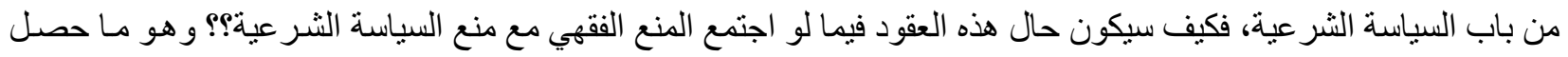

وبحسب الإحصائيات فقد بلغت قيمة المعاملات التي تجري في الأسواق المالية في يوم و احد وفق هذه العقود أكثر من الناتج

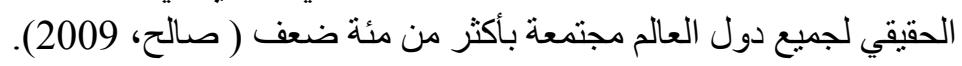

تعريف العقود المستقبلية: لقد عرفت العقود المستقبلية بتعريفات كثيرة، منها: أن العقود المستقبلية هي عقود تعطي لحاملها الحق في شر اء أو بيع كميـة معينة من أصل معين بسعر محدد مسبقاً، على أن يتم التسليم و التسلم في تاريخ لاحق في المستقبل المعائ معتصم، 2007).

\section{خصائص العقود المستقبلية:}

للعقود المستقبلية عدد من الخصائص أهمها( خيري، 2005): 1- هي عقود بيع وشر اء، وبالتالي فهي ليست و عداً أو دعوة للتعاقد، بل هي عقد بيع.

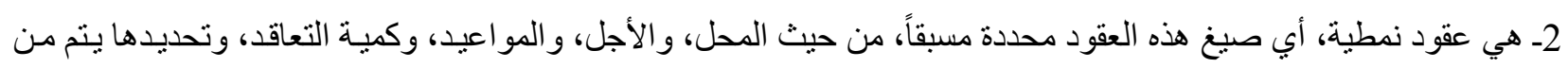
قبل هيئة السوق، ولا يملك المنعاقد تغيير أي بند فيها، بـل يملك القبول أو الرفض لكامل العقد فقط، وبالتالي تعتبر من عقود الإذعان.

و الحد الأدنى لكمية التعاقد هو حد محدد مسبقاً كما سبق، ويجري التعاقد على هذا الرقم أو على مضاعفاته، و لا يوجد أجز اء أبداً. 3ـ هي علاقة غير مباشرة بين طرفي العقد، بل تتم إمـا عن طريق السماسرة، أو عن طريق غرفة المقاصـة، التي تتوكل عن الطرفين كل تجاه الآخر.

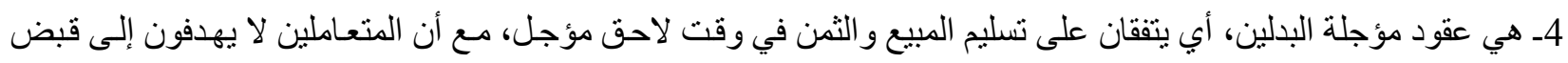

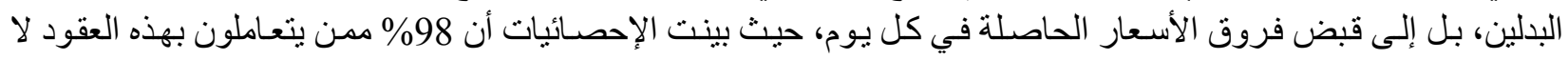
يهدفون إلى البيع والثراء و القبض، بل إلى المضاربة و الحصول على الإسلى فروق الأسعار.

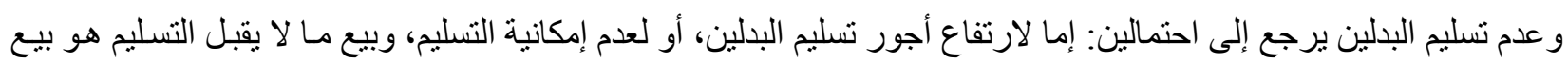

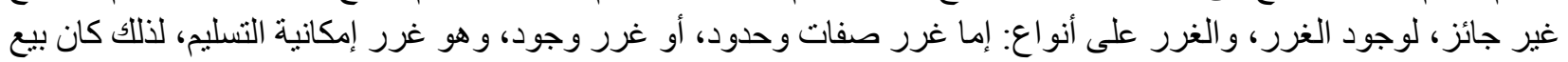
السمك في الماء، و الطير في الهواء، و العبد الآبق، والحيو العيوان الثارد، كل ذللك من البيوع المنهي عنها غير الجائزة. 5ـ حتى تستوثق هيئة السوق من جدية المتعاملين تطلب هوامش، و هو جزء من المسال تحتجزه هيئة السوق تأميناً على حسن نو ايا العاقدين.

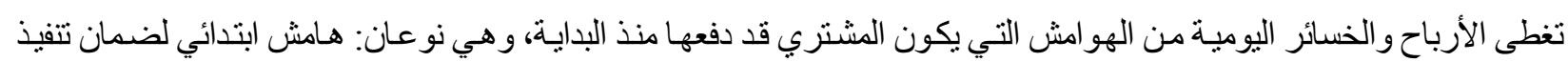

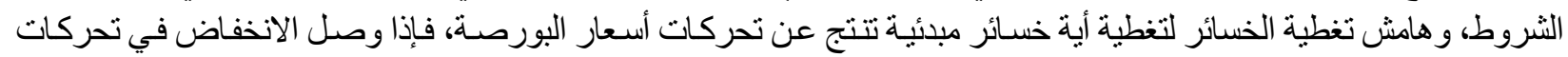

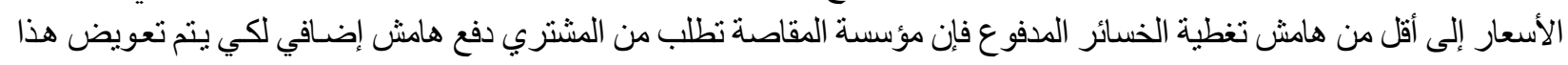
الانخفاض في الأسعار.

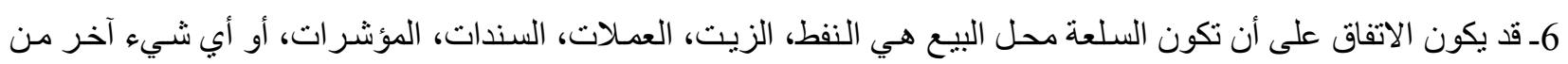

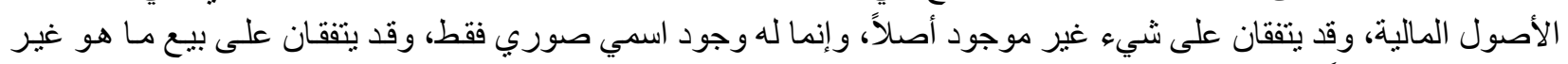
مملوك للبائع أساساً.

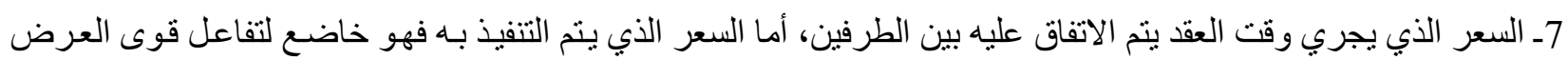

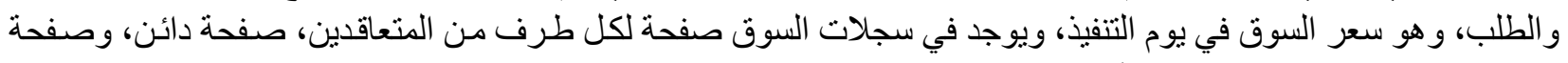
مدين، وفي كل يوم يتم النظر إلى الأسعار فإن حصل ارتفاع سجل في صفحة الدائن، و إن حصل الانخفاض سجل في في صفحة 
المدين، و هكذا في كل يوم حتى يوم التنفيذ، حيث تحصل التسوية وتحصل المقاصة بين الطرفين، وبذللك يتحقق الربح و الخسارة

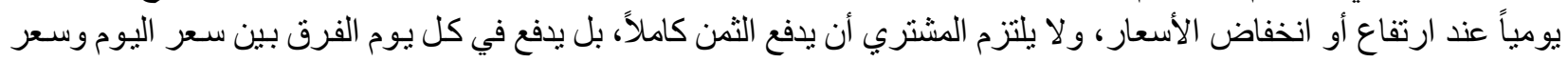
يوم التعاقد. إذا توقف أحد الأطر اف عن الوفاء بالتز اماته يقوم السمسار أو هيئة السوق بإجر اء صفقة عكسية، ويتم إغلاق حسابه، ويقتطع الفرق من الهامش الذي دفعه بداية.

\section{الأصول التى يجري التعاقد عليها:}

سبق أن ذكرنا في خصائص هذه العقود أنـه قد يكون محل العقد نفطاً، أو زيتاً، أو عملة، أو مؤشراً، أو أصلاً مالياً، ولكن الأصول

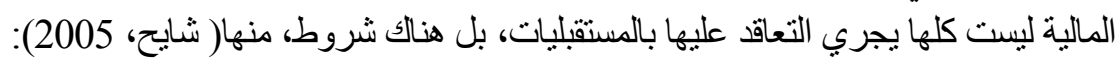

$$
\text { 1- أن تكون المادة قابلة للتنميط كما سبق. }
$$

2-و جود طلب نشط على هذا الأصل، بما يحقق له السيولة و الرواج في أي وقت.

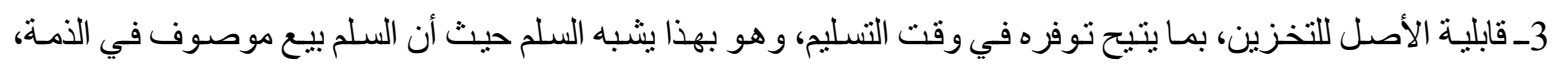

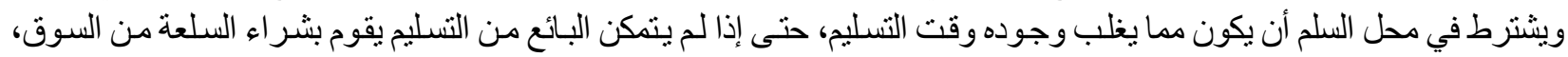
وتسليمها للمشتري في المو عد المحدد. 4ـ أن يكون ذا قيمة دقارنة بحجمه، ويكون التعاقد بأحجام كبيرة، ويرضون بالفرق السعري القليل؛ لأن التغير القليل في السعر هو في الحقيقة تغير كبير مقارنة بالحجم الكبير.

\section{ملاحظات هامة:}

1ـ كثير من التعاريف حاولت توصيف هذا العقد بأنه عقد معلوم محدد، و الهدف من هذه التعريفات هو بيـان أنها تقاس على مئى

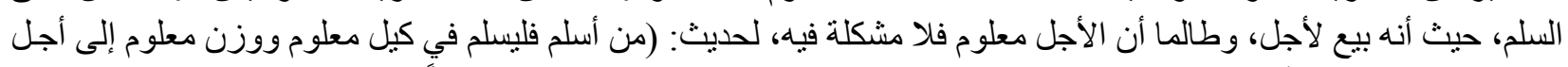
معلوم)، وجميع هذه الأشياء معلومة في العقود المستقلية، فتكون العقود المستقبلية جائزة قياساً على السلم.

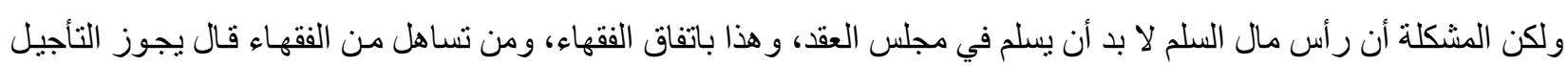

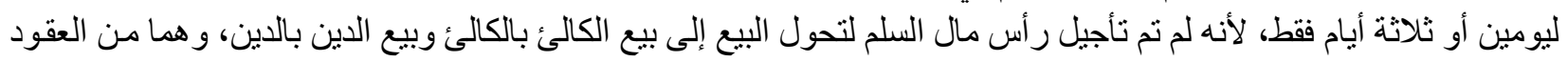
المحرمة والمنهي عنها. 2ـ لفهم كل قضية وكل عقد لا بد أو لاً من تجريده إلى عناصره الجو هريـة الأساسية، بأن نحذف الصفات و التفريعات، ونبقي الأركان

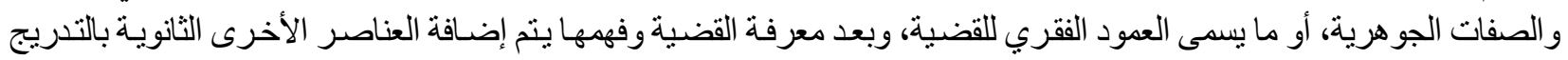
بحسب الأهمية، حتى يتم فهمهاو الإحاطة بها. 3ـ كلمة البيع هي من الأضداد، حيث تعني البيع والثر اء، وذكر كلمة البيع يغني عن ذكر كلمة الثر اءه، لأنه لا يتم البيع بدون

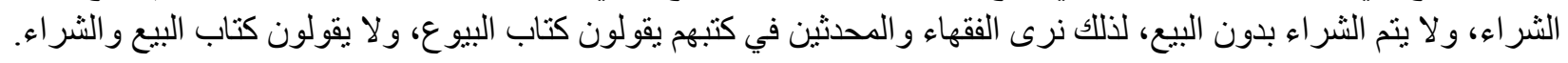

\section{التكيف الفقهى لعقود المستقبليات وحكمها:}

اختلف العلماء المعاصرون في التكييف الفقهي لعقود المستقبليات، وبالتالي اختلف حكمهم عليها ما بين مجيز ومانع (العبد الو هاب،2010).

الفرع الأول: المجيزون لعقود المستقبليات: اعتمد المعاصرون في حكمه على هذه العقود بالجواز على بعض التخريجات، ومن ذلك:

أولاً: قياسها على السلم: ذهب بعض المعاصرين إلى قياس العقود المستقلية على عقد السلم في الفقه الإسلامي، حيث أنه إذا ما

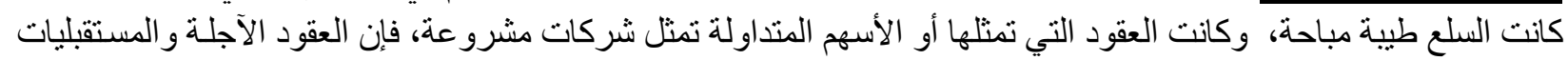

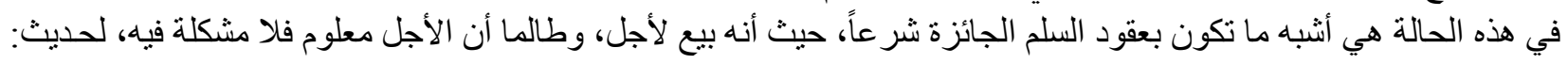


(من أسلم فليسلم في كيل معلوم ووزن معلوم إلى أجل معلوم)، وجميع هذه الأشبياء معلومـة في العقود المستقبلية، فتكون العقود

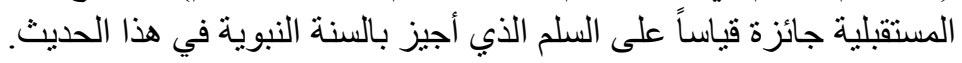
ويعرف عقد السلم بأنه بيع موصوف في الذمة محصور في الصفة بوزن معلوم وكيل معلوم إلى أجل معلوم، وقد أجيز هذا البيع استثناء لثدة الحاجة إليه كما أثنار جمهور الفقهاء.

ويعترض على هذا التخريج بوجود فروق كثيرة بين عقد السلم و العقود المستقبلية، أهم هذه الفروق أن رأس مال السلم في

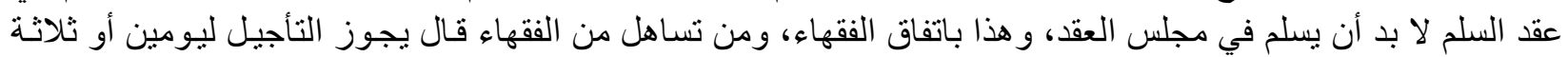

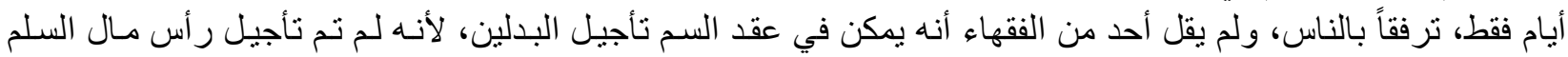

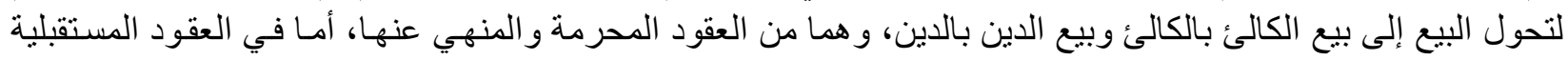

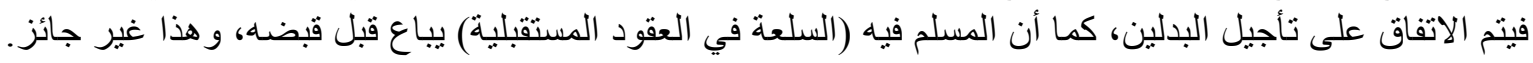

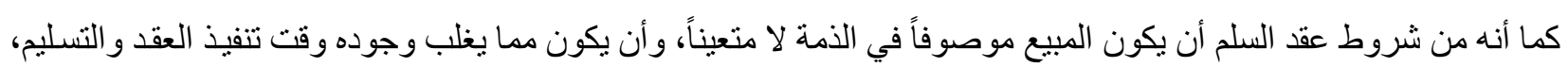

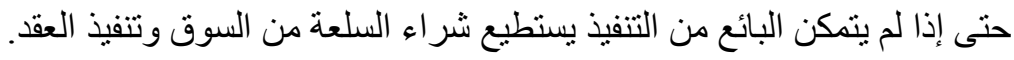

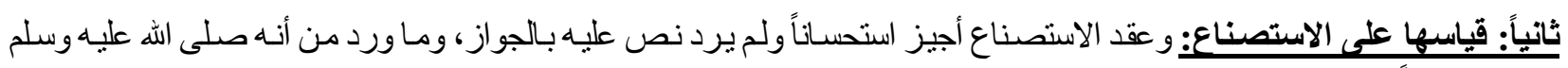

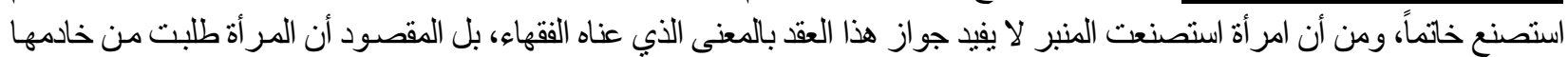

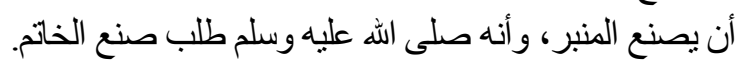

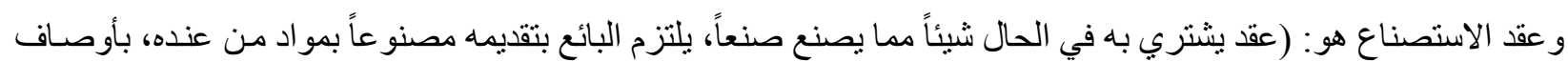

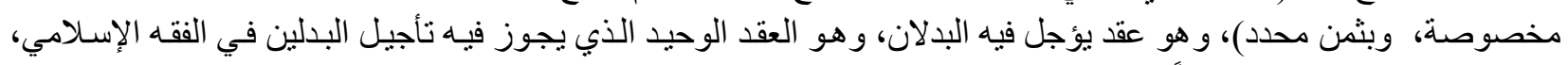

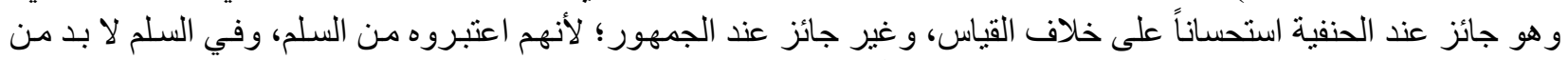
تسليم رأس المال، أما هنا فيجوز تأجيل رأس المال أيضاً.

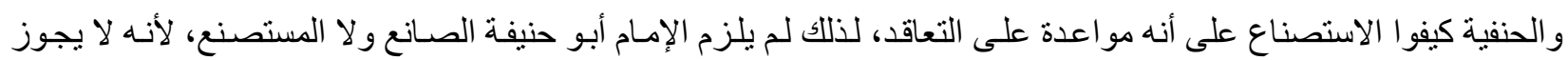

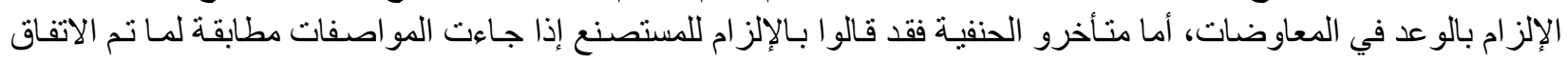

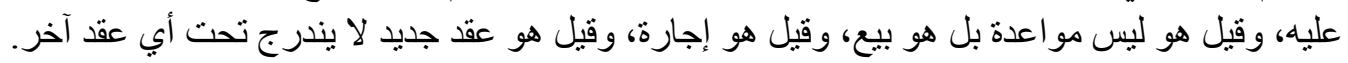
ويشترط في الاستصناع أن تكون السلعة مما يدخل فيها العمل، فلا يصح أن تكون سلعة زر اعبـة مثناً، وتكون مـادة العمل من

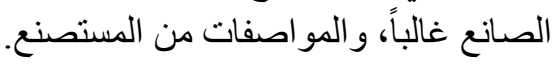

بعد ذكر هذه النبذة الموجزة عن الاستصناع نرى أنه هل يمكن قياس العقود المستقلية على الاسصناع؟ أم لا يمكن القياس؟ الحقيقة أنه لا يمكن قياس المستقبليات على الاستصناع للفروق الكثيرة بينهما، منها:

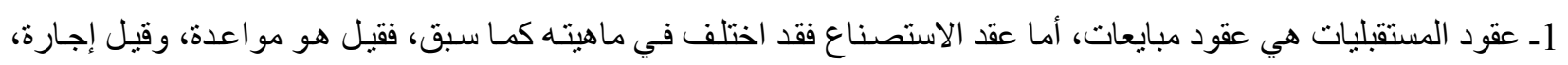

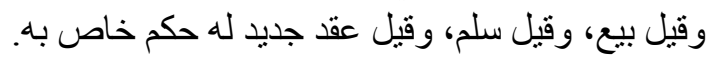
2ـ في الاستصناع المقصـود من التعاقد هـو الحصول على السلعة محل التعاقد، أمـا هنـا في المستقلبليات فليس المقصـود هو الحصول على السلعة بل المضاربة والحصول العصول على فروق الأسعار فقط.

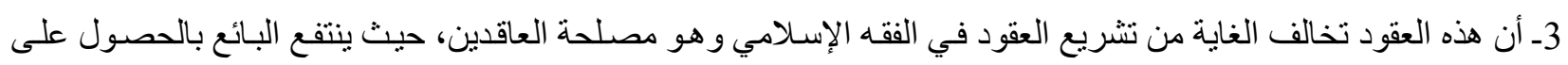

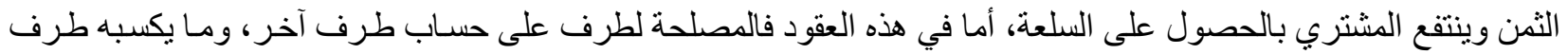
يخسره طرف ون الفن

4ـ بالإضافة إلى أن الاستصناع لم يرد نص عليه بالجواز، وبالتالي لا يصح القياس عليه، لأن ما يصح القياس عليه لا بد أن برد عليه نص بالجواز.

ثالثاً: تخريجها على أنها وعد: وبالتالي لا مانع منها. 


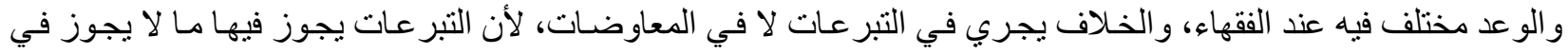

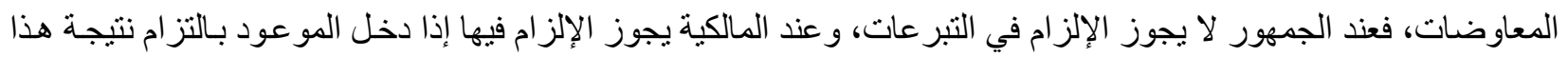
الو عد.

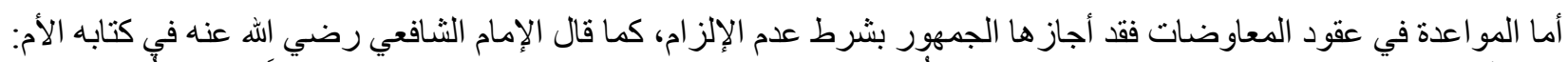

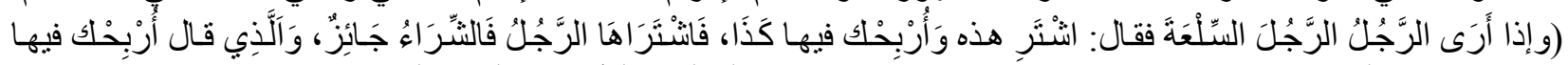

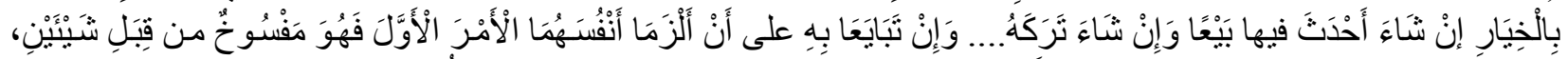

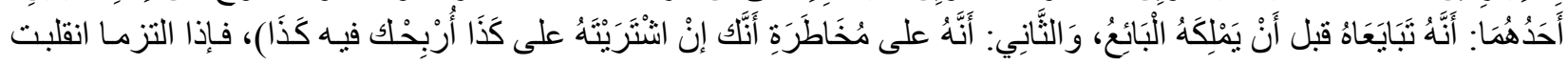

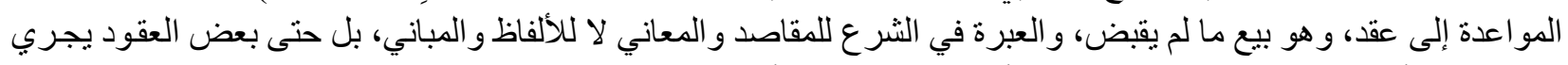
فيها الخيار، أما هنا لو قلنا بالإلز ام فلا خيار لأحد الطرفين، فهي أشند من العقد. و المالكية أيضاً منعو ا المو اعدة في المعاوضات أيضاً، و اعتبروها من بيوع العينة المحرمة. فهل تعتبر المستقبليات فعلاً من قبيل الوعود؟؟ أم هي على غير ذلك؟؟ 1_المستقبليات ليست و عداً مطلقاً، بل هي عقد بيع، وهذا ما يصر ح به كل القانونيين و الاقتصساديين في تكيفههم لهذا العقد، وهم يسمونها عقوداً أصلاً. 2ـ حتى لو كانت و عداً فقد ر أينا أن الو عد لا يجوز الإلز ام به في المعاوضات، لأنه يؤدي إلى بيع مـا لم يقبض، ولوجود الغرر كما صر ح بذللك الإمام الثافعي.

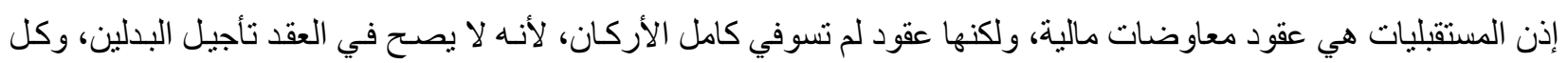

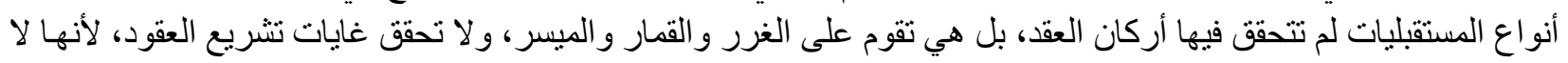

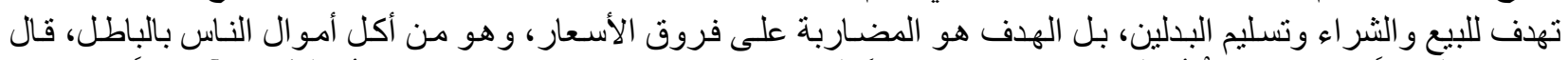

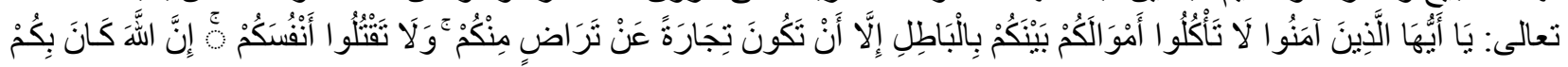

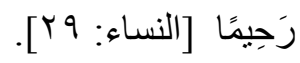

\section{رابعاً: هي بيع موصوف في الأمة بلفظ البيع، مؤجل فيه الثمن}

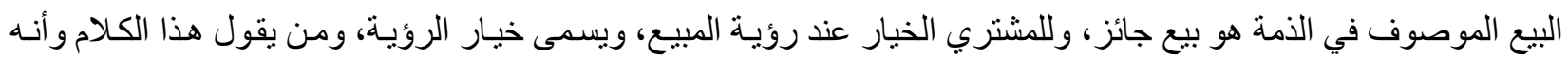

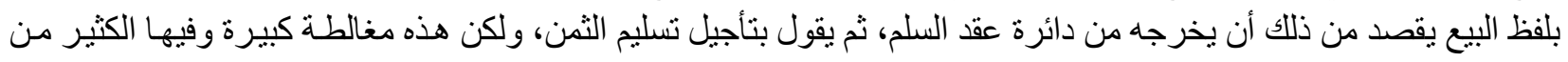

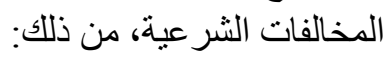

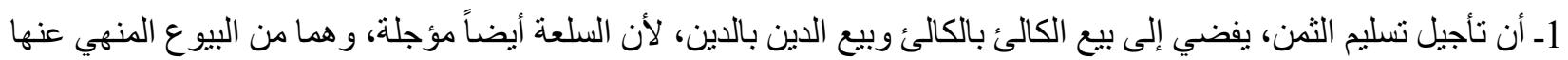

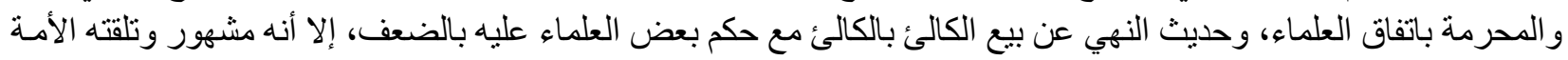
بالقبول، فيجب الأخذ و العمل باه.

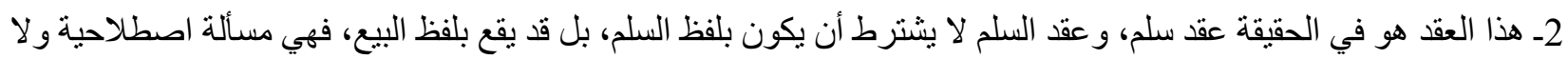

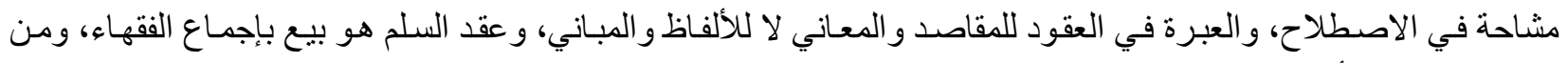
شروط عقد السلم أن يتم تسليم الثمن في مجلس العقد، حتى لا يفضي العقد إلى بيع مؤجل البدلئ لإلئ. 3ـ بالإضافة إلى سبق من المناقثات من مخالفة هذه العقود للغاية من تشريع العقود في الثريعة الإسلامية. كما أن الحكم على مشروعية أب عقد من العقود ينوقف على عدد من الأمور، منها: 1ـ سلامة النية و الباعث، لحديث: (إنما الأعمال بالنيات، و إنما لكل امرىئ مانوى).

2- سلامة محل العقد ومشرو عيته.

3ـ أهلية المتعاقدين، بنو عيها الأهلية المعرفية والأهلية الحقوقية. 4ـ الخلو من الموانع كالغرر و الربا والميسر و القمار و الجهالة، و غير ذلك. 


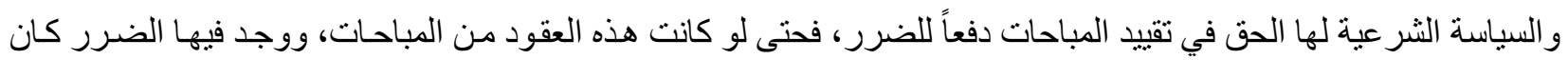

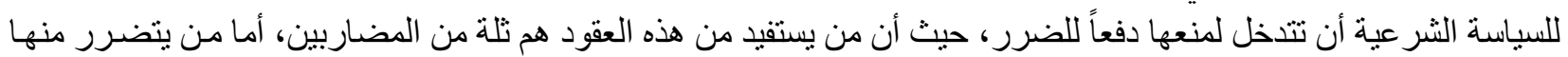

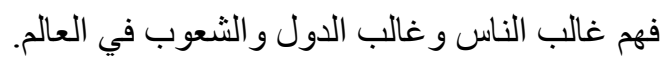
ملاحظة: الأموال قسمان: أعبان، وديون، والأعيان تطلق على الثيء المادي كالسلع، وتطلق على المال الحاضر ، أما الدين فهو

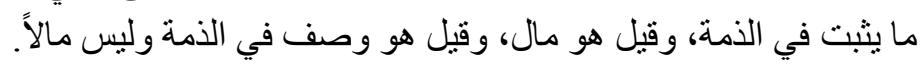
وبعض المعاصرين اعتبر ها من باب القياس على بيع الغائب، ولكن بيع الغائب هو بالأصل مختلف في مشرو عيته، ومن أجازه

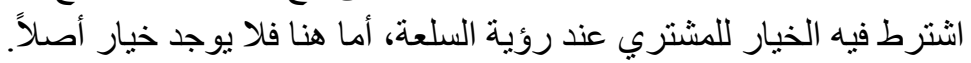

كما أنه من شروط البيع أن يكون المبيع موجوداً وقت التعاقد، لذلك ورد النهي عن بيع غير الموجود، كالملاقيح والمضامين، وحبل الحبلة، أبي أن يكون المبيع ناجز أ حاضر أ قابلاً للتسليه.

وبعض المعاصرين قاس المستقبليات على قصة وحديث سيدنا جابر رضي الله عنه، حيث اثشترى من النبي صلى الله عليه وسلم

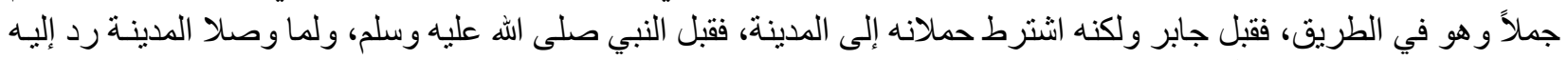

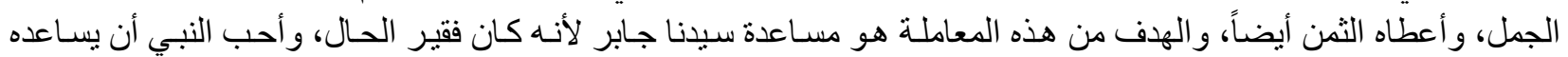
بطريقة غير مباشرة.

ووجه القياس أن المستقبليات هي بيوع مؤجلة البدلين، و هنا أيضاً تم تأجيل البدلين في هذا البيع. ولكن الحقيقة أن هذا القياس لا يصـح، لأن الحديث لبس دليلاً على مشروعية البيع المؤجل البدلين، وليس فيه تأجيل للبدلين

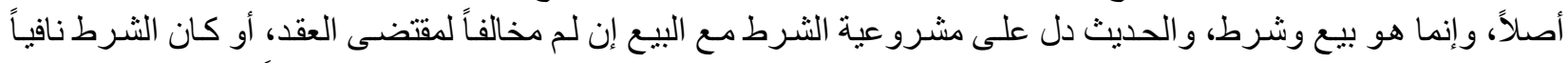

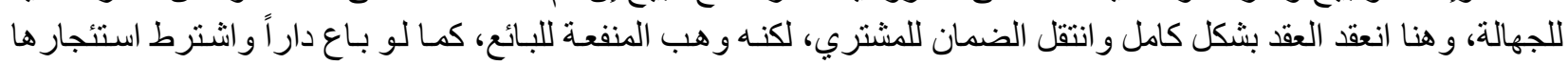
لمدة محددة، فهو قد استأجر المنفعة بجز اءعة من الثمن. الفرع الثانى: المانعون لعقود المستقبليات:

ذهب أكثر المعاصرين إلى تحريم التعاقد بالعقود المستقبلية، وكذللك جاء حكم المجامع الفقهية بمختلف أنواعها، وكذللك جاء قرار

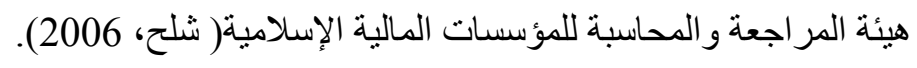

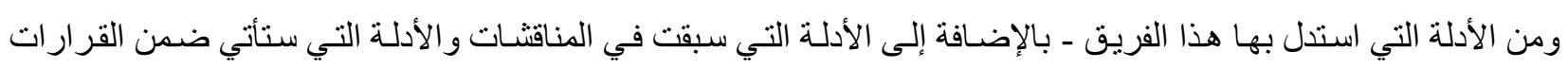

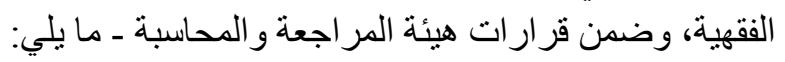

1- بالنسبة إلى المبنى العقدي، هنـاك خلل واضـح، و هو أنها بيوع مؤجلة البدلين، وهي بيوع منهي عنها، ومحرمـة بإجماع العلماء.

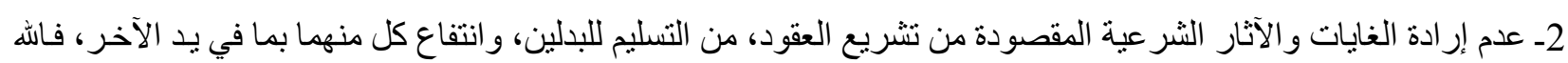

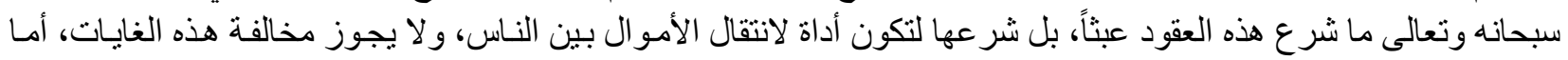

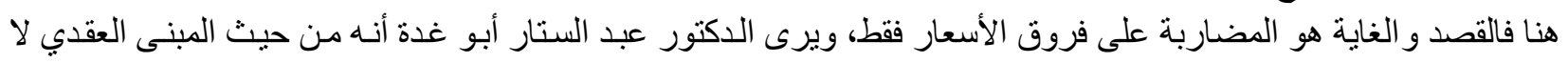

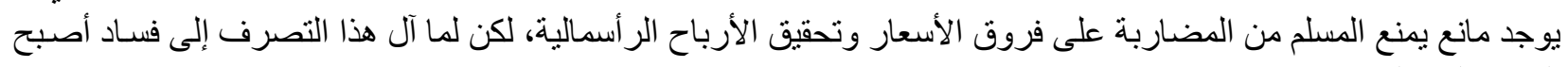
الحكم عليه بالمنع.

\section{عقود المستقبليات على العملات:}

سابقاً كان التعامل بين الناس عن طريق النقود المعدنيـة كالذهب و الفضـة، وكان سعر الصـرف المحدد هو 1 دينـار = عشرة

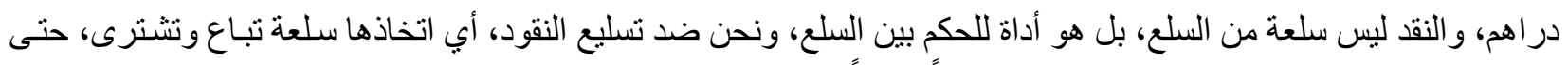

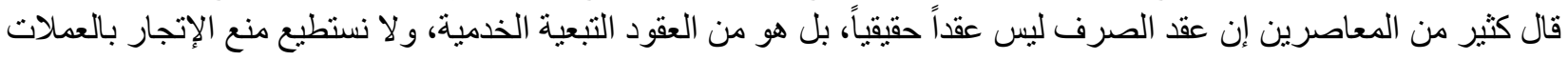

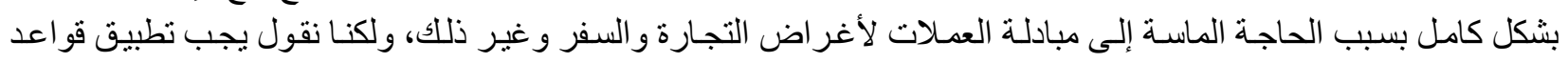


وأحكام وشروط عقد الصـرف في الفقه الإسـام على بيع وشر اء العملات، من اشتر اط التقابض في مجلس العقد، و اشتراط معلومية ويقين التماثل، و عدم الخيار و الجز اف و والأجل.

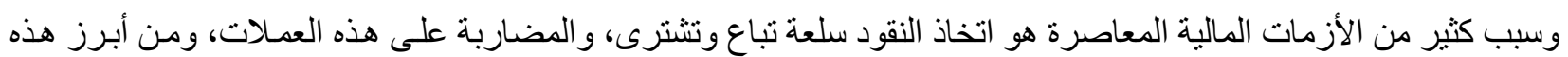

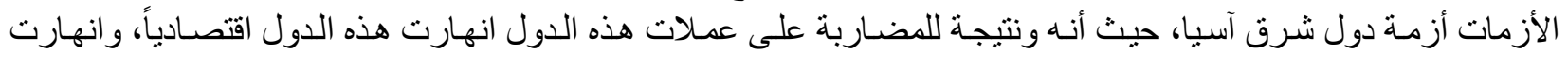

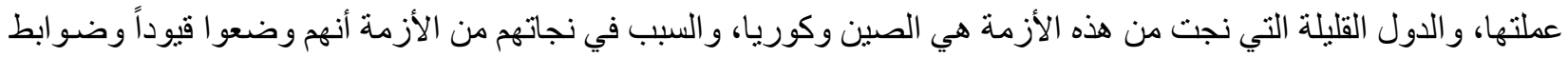

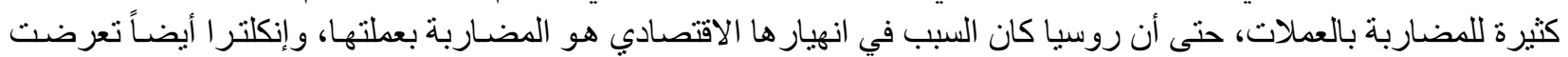

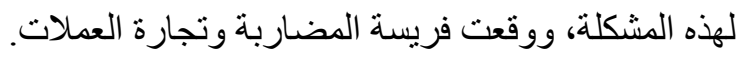

و السياسة الثرعية لها دور كبير في منع هذه الممارسات الضارة بالأفر اد و المجتمع، و النبي صلى الله عليه وسل يقول: (إن الله ليزع بالسلطان ما لا يزع عالقر لهر آن). ومشكلة أغلب الدول العربية والإسلامية في الأسواق المالية هو الذيلية والتبعية للغرب في هذه الأسواق، و اتباع المغلوب للغالب،

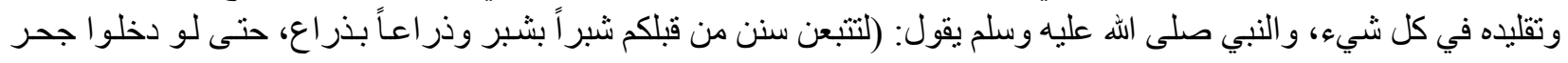
ضب للخلتموه ور اءهم) ( العبد الو هاب، 2010).

\section{قرارات المجامع الفقهية بشأن العقود المستقبلية:}

أ ـ نص قرار مجمع الفقه الإسلامي في دورته السابعة المنعقدة في جدة في عام 1412هـ، وكذللك البيان الختامي لندوة الأسواق النهاق

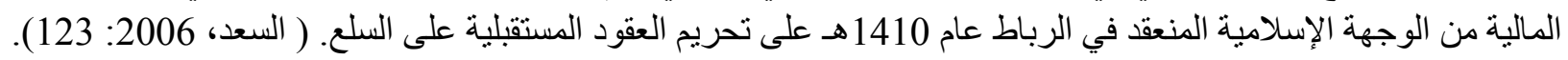

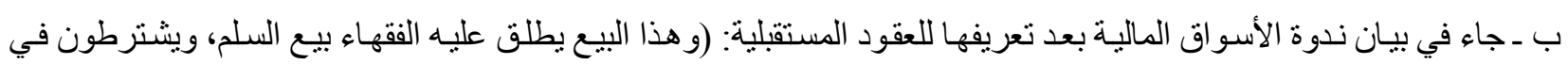

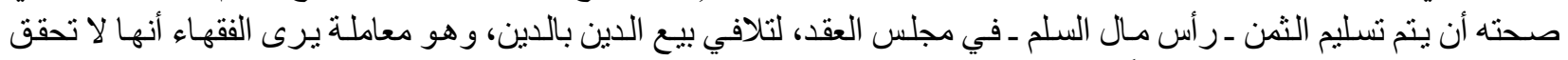

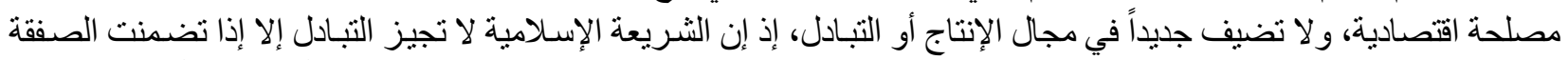

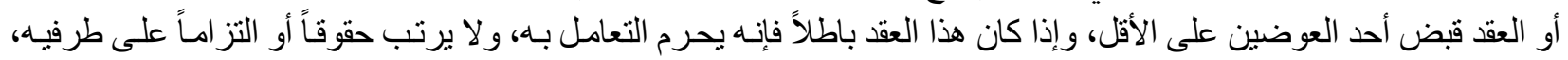

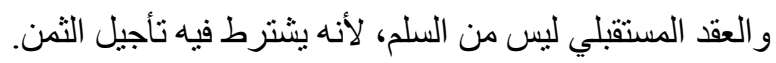
ج ـ نص قرار مجمع الفقه الإسلامي في العدد 6، الجزء 1664/2 ، ولى على ما يلي: (يتم التعامل بالسلع في الأسواق المنظمة بإحدى أربعة طرق،

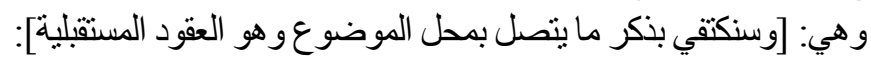

الثالثة: أن يكون العقد على تسليم سلعة موصوفة في الذمة، في مو عد آجل، ودفع الثمن عند التسليم، وأن يتضمن شرطاً يقتضي

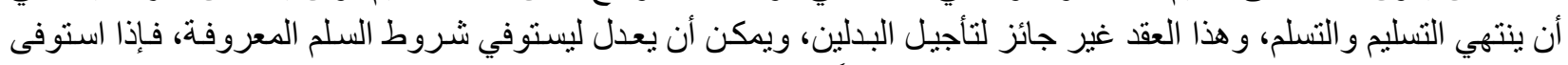

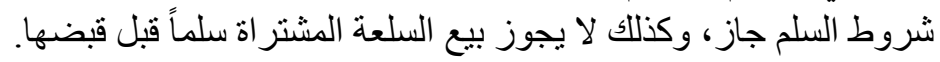

الر ابعة: أن يكون العقد على تسليم سلعة موصوفة في الذمة، في مو عد آجل ودفع الثمن عند التسليم، دون أن يتضمن العقد شرطاً

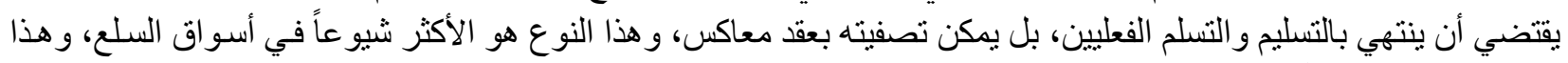
العقد غير جائز أصلاً.

فإن قيل إن الغرض من هذه العقود هو الاحتياط، وفيها مصلحة المتعاقدين، وهي التأمين ضد خطر تقلب الأسعار، وقد جاءت إتباء

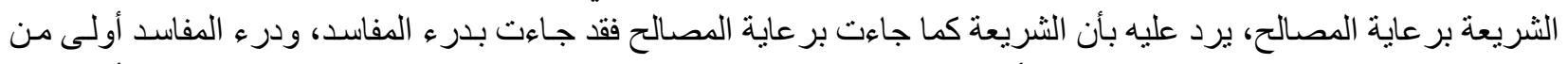

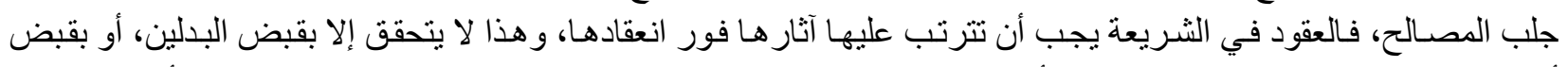

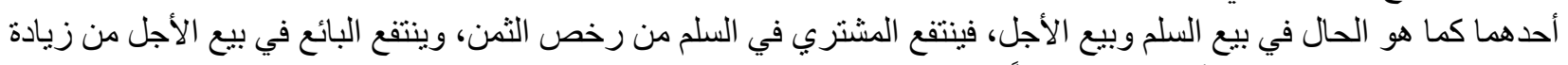

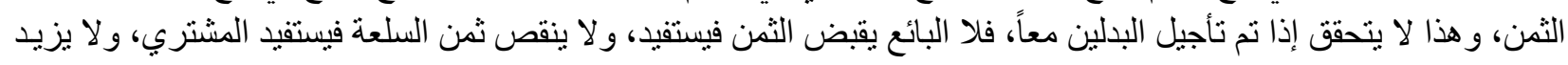

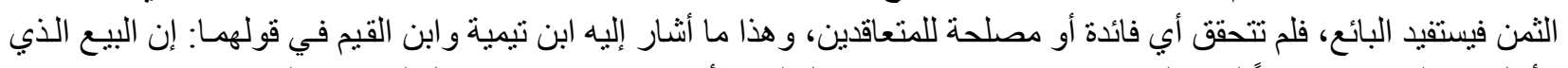

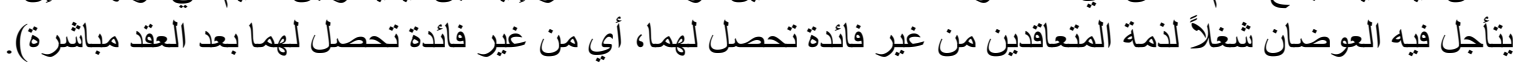
دـ تناول مجمع الفقه الإسلامي في دورته السابعة المنعقدة بجدة عام 1412 هـ مسألة العقود المستقبلية على مؤشر ات الأسهم،

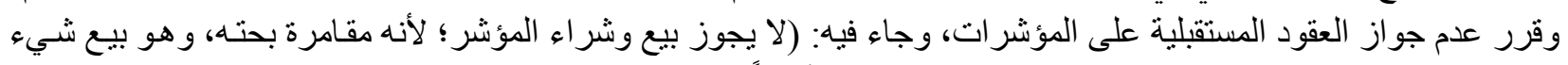

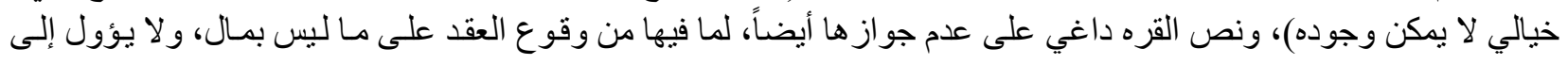


مال، لأن من شروط المعقود عليه أن يكون مالاً أو حقاً متعلقاً بمال، ومؤشرات الأسهم ما هي إلا أرقام مجردة، يقع العقد عليها، وليس على الأسهم الممثلة في تلك المؤشر داته). هـ ـ ناقش مجمع الفقه الإسلامي في دورته السابعة المنعقدة في جدة عام 1412هـ مسألة العقود المستقبلة على العملات، و أفتح بتحريمها كما سبق في الصور الثنالثة و الر ابعة.

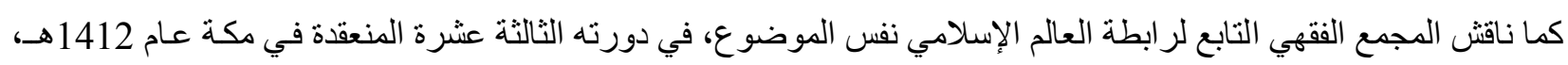

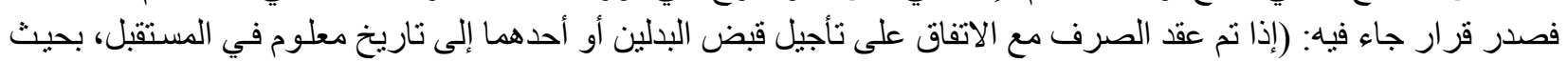

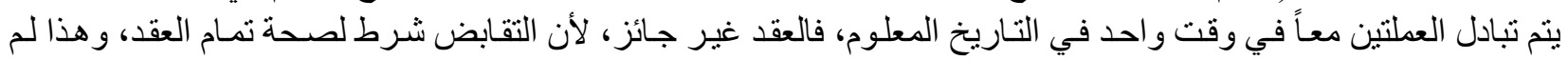

يتحقق).

وبحث المسألة أيضاً الدكتور علي القره داغي فقال بتحريم العقود المستقبلية على العملات مستدلاً بعدة أدلة، وهي: 1- إنها من قبيل بيع الدين بالدين، لأنه يتم تأجيل تسليم الثمن و المثمن.

2ـ تشتمل هذه العقود على ربا النسيئة المجمع على تحريمه، لأن العملات تشترك مع الذهب و الفضــة بعلة الثمنيـة، فيشترط عند

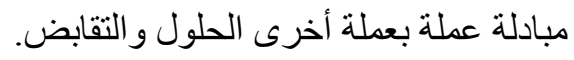
3ـ إذا انتهت هذه الصورة بالتسوية النقدية، و المحاسبة على فروق الأسعار فتكون بصورة مقامرة، لأن التسليم و التسلم لم يكن

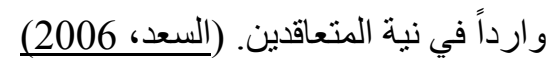
ويلاحظ على هذه القرار ات أنها ركزت على المبنى العقدي فقط، ولم تركز على المألات و النتائج لهذه العقود. وسـوف أورد في نهايـة المحاضـرة ملحقـاً عن العقود المستقبلية وعقود المبـادلات مـن المعايير الثـرعية الصـادرة عن هيئة المر اجعة و المحاسبة للمؤسسات المالية الإسلامية.

عقود المبادلات:

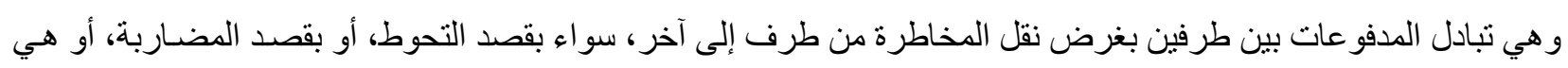

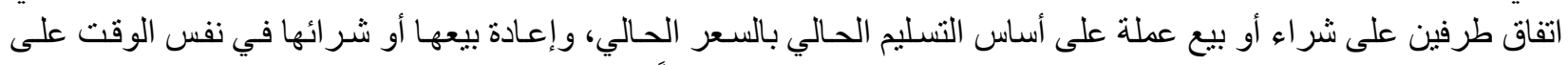

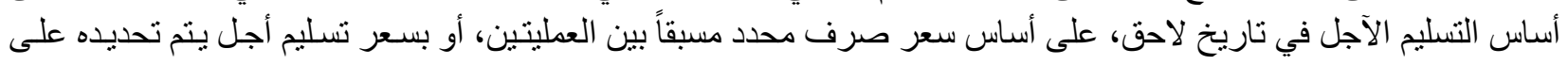
أساس فروق أسعار الفائدة على القروض لاحق، والو الودائع بين العمليتين( عبد الغفار، 2012).

المقارنة بين العقود الآجلة (المبادلات) و العقود المستقبلية:

تكمن المقارنة بين هذين النو عين من العقود في النقاط التالية:

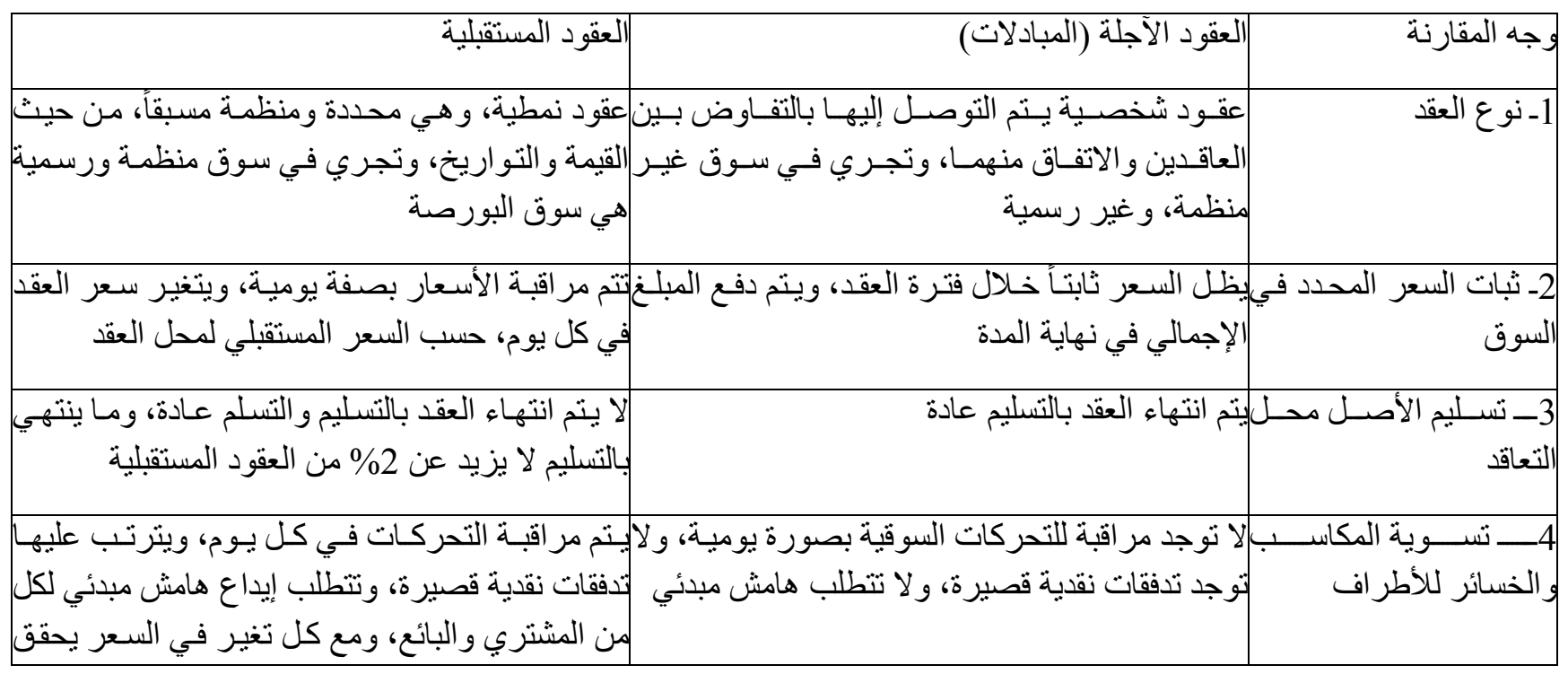




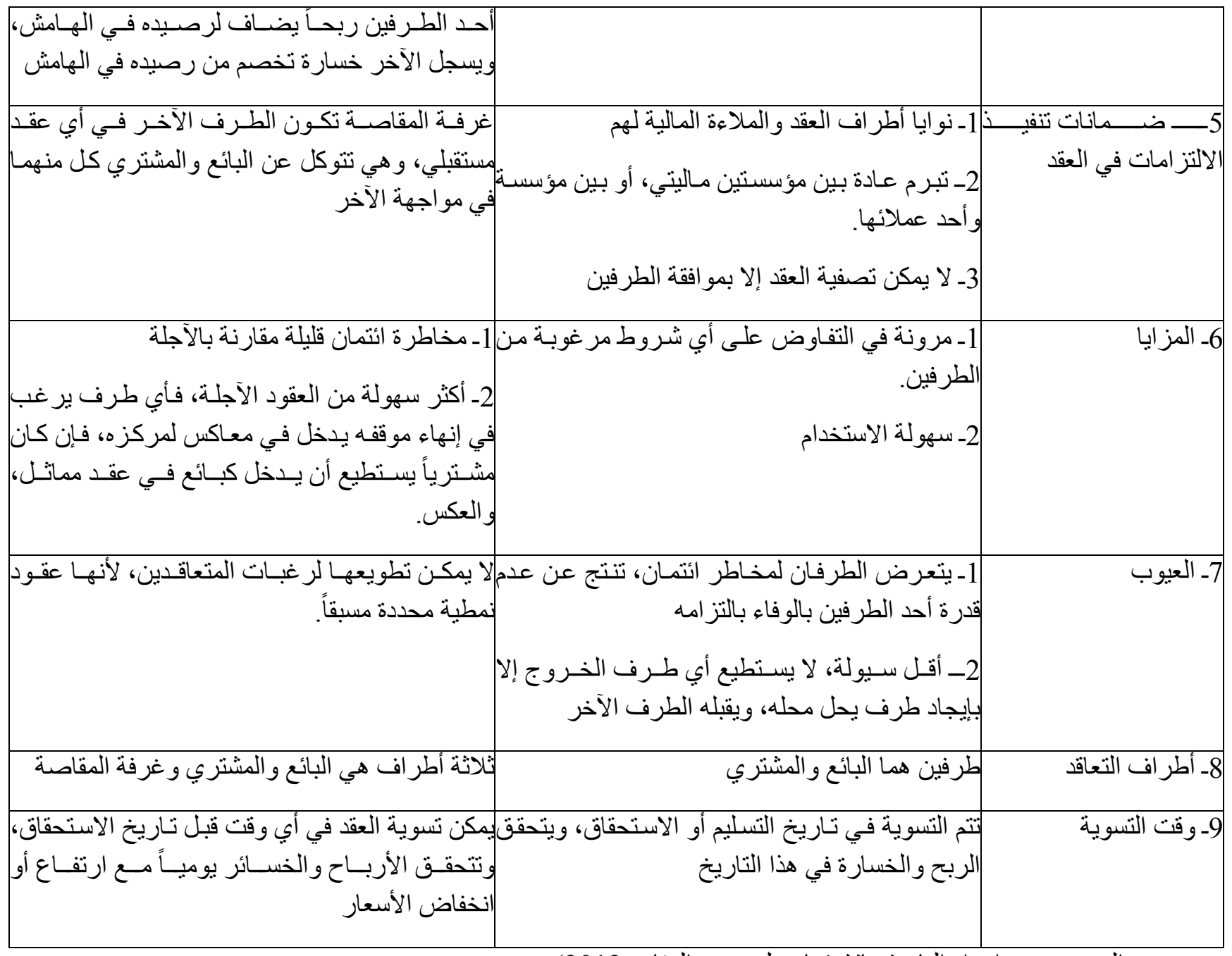

المصدر: من إعداد الباحث بالاعتماد على، عبد الغفار، 2012)

كما أن الدخول للأسو اق المالية إما يكون بهدف السيولة أو بهدف التمويل أو بهدف الربح، و العقود النمطية أكثر قدرة على تحقيق هذه الأهداف.

\section{أسباب استخدام عقود المبادلات:}

أو لاً: على مستوى الأفر اد: تستخدم من قبل الأفر اد للأسباب التالية: 1ـ الحصول على الفرق بين معدلات الإقراض في الأسواق المعومة، وتللك الأسعار الثابتة. 2- هي أداة لإدارة المخاطر و التحوط. 3ـ منخفضة التكلفة. 4ـ تتمتع بمرونة عالية. ثانياً: على مستوى المصارف التجارية: تستخدم من قبل المصارف للأسباب التالية: 1ـ تحقيق الربح فضلاً عن تحقيق إدارة أفضل للموجودات. 2- مواجهة التز امات المصارف المختلفة خاصة المستقبلية. 3ـ تستعمل من قبل السلطات النقدية في ظروف مختلفة لتغذية الجهاز المصرفي بالسيولة المحلية المؤقتـة. 4- إيجاد وضع آجل مقابل وضع آجل. 


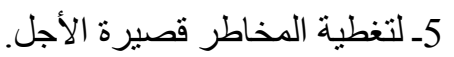

و الحقيقة إن الثخص ليس مضطر اً للاخول في الأسواق المالية وتحمل هذه المخاطرة، حتى يلجأ إلى هذه العقود للتحوط من هذه

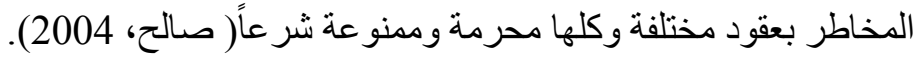
أنواع عقود المبادلات: تجري عقود المبادلات وفق نوعين( عفت، 2007):

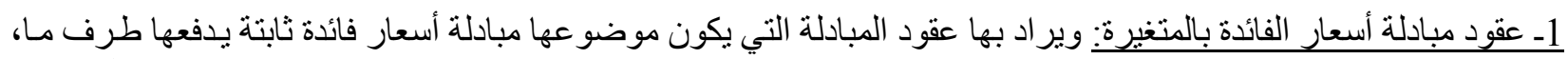

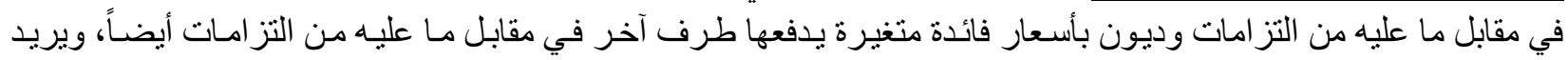

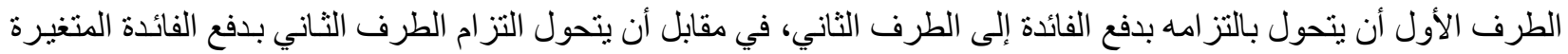

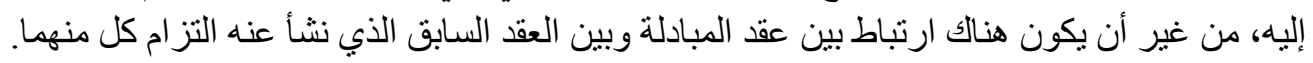

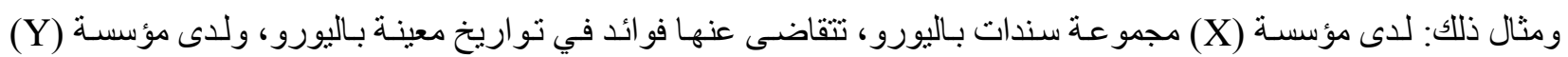

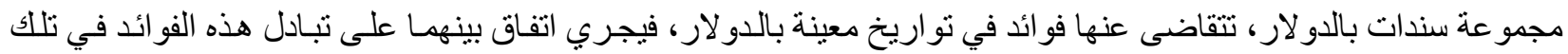

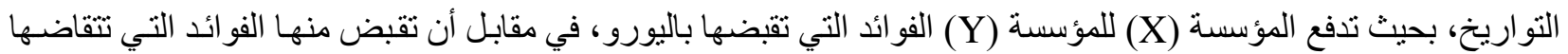

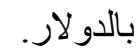

وقد تكون إحدى هذه الفو ائد ثابتة و الأخرى متغيرة. و الفائدة أنو اع: فائدة بسيطة، و هي تحسب مرة واحدة عند بداية التعاقد، وفائدة مركبة، وهي تر اكمية، أي هي الفائدة على الفائدة، لو حل الأجل ولم يتمكن من السداد تتر اكم الفائدة مرات عدات عديدة. و هناك فائدة عقدية تتحدد نسبتها في العقد و القانون، و هنالك فائدة معومة، و هي تتم وتتحد حسب سعر السوق، و هذه بالإضـافة إلى لى

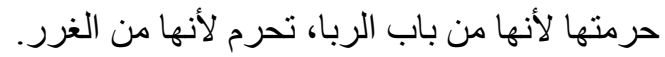

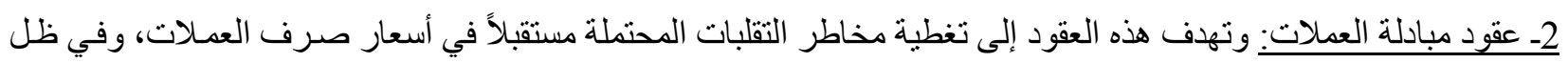

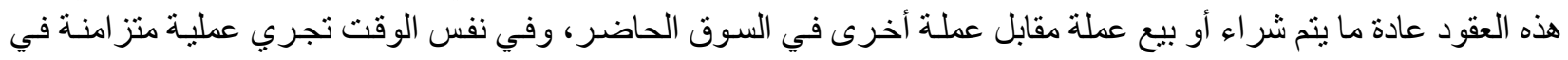
السوق الآجل، وذلك لبيع العملة التي سبق شر اؤه عاؤها أو شر اء العملة التي تم بيعها. التالية: ذللك: أن يتفق شخص مع أحد البنوك على إجر اء مبادلة الدينار الجزائري بالدو لار الأمريكي، وفقاً للخطوات والثروط

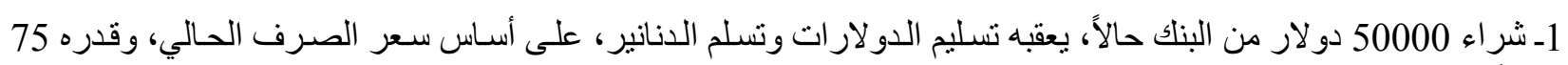

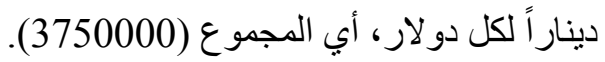

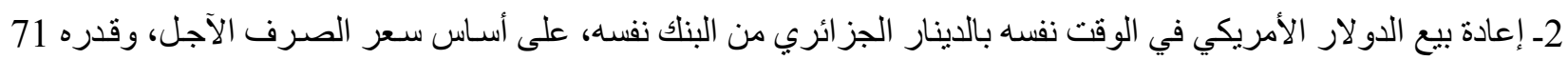

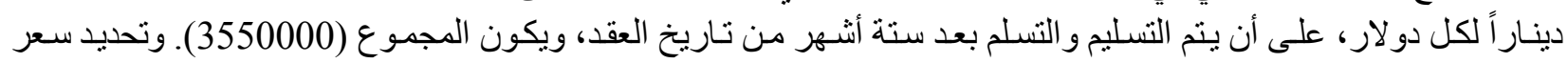
الصرف الآجل يتوقف على مقدار معدل الفائدة على الإقر اض والئ الإيداع بالنسبة لكلا العملتين.

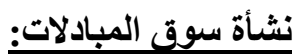

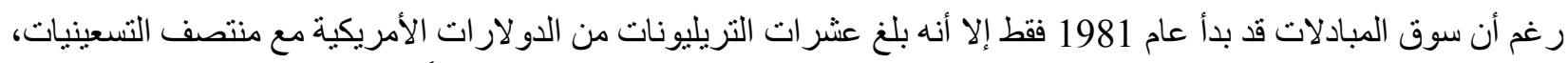

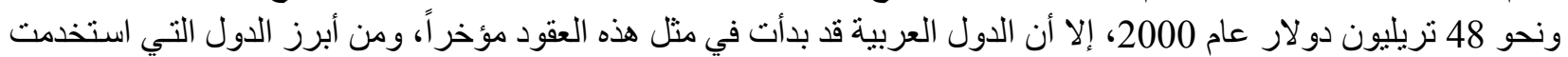
عقود المستقبليات و المبادلات هي السعودية.

المراجع

[1] ابن القيم، (1991). إعلام الدوقعبن عن رب العالمبي، دار الكتب العلمية، الطبعة الثانية. [2] السعد، احمد، (2006). الأسواق المالية الدعاصرة، الطبعة الأولى. [3] العبد الوهاب، سعد، (2010). الأسواق المالية، دار الهجرة للنشر. 


$$
\text { [4] القران الكريم }
$$

[5] خيري، طارق، (2005). الأسواق المالية، مكتبة صالحين للنشر ، الطبعة الأولى. [6] شايح، عبد العالم، (2005). أحكام الدعاملات المالية، دار شذا الحبيب للنشر. [7] شلح، عبد الو هاب، (2006). الأسواق المالية، دار عرابة للتوزيع، الطبعة الثانية. [8] صالح، محمود، (2004). عقود المستقبليات رؤية شرعية، مجلة الثـاهد الاقتصادي، عدد 7، المجلد2. [9] صالح، معتمد، (2009). الأحكام الثرعية للأسواق الدالية، دار الحمد للنشر والتوزيع. [10] عبد الغفار، فيصل، (2012). أسواق المال، دار الخير للنشر و التوزيع، الطبعة الثالثة. [11] عفت، محمد، (2007). العقود في الأسواق المالية، عشتار للطباعة، الطبعة الثانية. [12] معتصم، شكري (2007). المعاملات في الأسواق المالية، دار الوفاء للنشر. [13] وزارة الأوقاف و الثثؤون الإسلامية الكويتية (1983). الدوسوعة الفقهية الكوبيتية، المكتبة الثناملة. 